\title{
Collusion in a price-quantity oligopoly
}

Citation for published version (APA):

van den Berg, A. H. J., \& Bos, A. M. (2011). Collusion in a price-quantity oligopoly. METEOR, Maastricht University School of Business and Economics. METEOR Research Memorandum No. 039

https://doi.org/10.26481/umamet.2011039

Document status and date:

Published: 01/01/2011

DOI:

10.26481/umamet.2011039

Document Version:

Publisher's PDF, also known as Version of record

\section{Please check the document version of this publication:}

- A submitted manuscript is the version of the article upon submission and before peer-review. There can be important differences between the submitted version and the official published version of record.

People interested in the research are advised to contact the author for the final version of the publication, or visit the DOI to the publisher's website.

- The final author version and the galley proof are versions of the publication after peer review.

- The final published version features the final layout of the paper including the volume, issue and page numbers.

Link to publication

\footnotetext{
General rights rights.

- You may freely distribute the URL identifying the publication in the public portal. please follow below link for the End User Agreement:

www.umlib.nl/taverne-license

Take down policy

If you believe that this document breaches copyright please contact us at:

repository@maastrichtuniversity.nl

providing details and we will investigate your claim.
}

Copyright and moral rights for the publications made accessible in the public portal are retained by the authors and/or other copyright owners and it is a condition of accessing publications that users recognise and abide by the legal requirements associated with these

- Users may download and print one copy of any publication from the public portal for the purpose of private study or research.

- You may not further distribute the material or use it for any profit-making activity or commercial gain

If the publication is distributed under the terms of Article $25 \mathrm{fa}$ of the Dutch Copyright Act, indicated by the "Taverne" license above, 


\section{Maastricht University}

Anita van den Berg, I wan Bos

Collusion in a Price-Quantity Oligopoly

$\mathrm{RM} / 11 / 039$

\section{METEOR}

Maastricht University School of Business and Economics

Maastricht Research School of Economics

of Technology and Organization

P.O. Box 616

NL - 6200 MD Maastricht

The Netherlands 


\title{
Collusion in a Price-Quantity Oligopoly*
}

\author{
Anita van den Berg ${ }^{\dagger} \quad$ Iwan Bos ${ }^{\ddagger}$
}

August 2, 2011

\begin{abstract}
In the context of an infinitely repeated oligopoly game, we study (optimal) collusion among firms that have both price and quantity as a strategic choice variable. We consider two modes of production: production in advance and production to order. For both types of industry, we compare a price cartel with a price-quota cartel and analyze if and under what conditions firms prefer the latter to the former. We find three main results. First, when production is in advance of sales and market demand is relatively elastic, an additional agreement on outputs may be required to solve coordination and incentive problems. Second, if production is in advance of sales and market demand is relatively inelastic, then a price-quota cartel is always more profitable than a price cartel. Finally, with production to order, collusion may not be sustainable without a quota agreement.
\end{abstract}

Keywords: Cartels; Price-Quantity Competition; Semi-Collusion.

JEL Codes: L1; L4.

*The comments and suggestions of participants at the 2011 International Industrial Organization Conference in Boston, Luke Garrod, Jean-Jacques Herings, Ronald Peeters and Hans Peters are gratefully acknowledged. All opinions and errors are ours alone.

${ }^{\dagger}$ Department of Quantitative Economics, Maastricht University.

${ }^{\ddagger}$ Department of Organization \& Strategy, Maastricht University. Corresponding author at: P.O. Box 616, 6200 MD Maastricht, The Netherlands. E-mail: i.bos@maastrichtuniversity.nl. 


\section{Introduction}

"The Cournot story concerns producers who simultaneously and independently make production quantity decisions, and who then bring what they have produced to the market, with the market price being the price that equates the total supply with demand. The Bertrand story, on the other hand, concerns producers who simultaneously and independently name prices. Demand is allocated to the lowprice producer(s), who then produce (up to) the demand they encounter ... There are two differences in these stories: how price is determined (by an auctioneer in Cournot and by price "competition" in Bertrand), and when production is supposed to take place."(Kreps and Scheinkman (1983), p. 326.)

Both the Cournot and the Bertrand story have significantly enhanced our understanding of strategic firm behavior in oligopolies. Yet, both have also been subject to severe criticism. For instance, Cournot's model requires an auctioneer to determine the market price, whereas in practice prices are typically set by suppliers themselves. In this respect, Bertrand's story is more satisfactory. However, this model assumes that production follows the realization of demand, whereas in a great many industries production precedes sales. More generally, and independent of the timing of production, it seems more reasonable to assume that firms choose both their prices and production levels. This is true when producers compete, but no different when they collude.

The objective of this paper is to study (optimal) collusion among firms that have both price and quantity as a strategic choice variable. Towards that end, we analyze an infinitely repeated oligopoly game in which firms simultaneously make both price and production decisions in each period. We consider two modes of production: production in advance and production to order. With production in advance, production costs are incurred before a firm learns how much it will actually sell. By contrast, when production is to order, producers choose a price and a quantity that they are willing to sell at that price. Thus, the key difference between both settings lies in whether or not firms commit to a particular production level before the realization of demand. We therefore incorporate the Cournot and Bertrand story regarding the timing of production, but price decisions are made by the producers themselves (i.e., there is no auctioneer). 
In attempting to combine the more plausible elements of both stories, existing literature has primarily focused on settings in which firms first choose production capacities and then engage in price competition. The reason for analyzing price competition given capacities is that prices can presumably be adjusted more quickly than quantity-related variables. For example, Kreps and Scheinkman (1983) finds that Bertrand competition may yield Cournot outcomes when suppliers first choose a scale of operation. As to collusion, Fershtman and Muller (1986) explores the impact of long-run competition in capital investments on collusion on prices and market shares and shows, among other things, that competition in capacities has no destabilizing effect on collusion. Benoit and Krishna (1987) finds that when firms are allowed to collude on both price and capacity then all collusive equilibria have firms holding excess capacity. Davidson and Deneckere (1990) establishes that more collusion requires higher levels of excess capacity. Holding excess capacity is required to enforce a collusive scheme as it allows to punish a deviator by increasing production. In the current paper, we assume that firms adopt grim-trigger strategies to sustain collusion and that there is sufficient production capacity to implement this punishment strategy. Consequently, our focus is on actual output decisions and not on the maximum amount of products a firm can offer each period.

To our knowledge, this paper is the first to study collusion in a price-quantity oligopoly while taking account of different timing of production. ${ }^{1}$ As suppliers have control over both price and quantity, one question of interest is what choice variables they will optimally collude on. Will they choose to collude on price or quantity (semicollusion) or both (full collusion)? ${ }^{2}$ In this study, we restrict attention to price collusion and price-quantity collusion. Put differently, firms are given the possibility to either form a price-fixing cartel or a price-quota cartel. ${ }^{3}$ Clearly, as full collusion allows firms to mimic semicollusion, full collusion in principle generates (weakly) higher profits. Yet, there are at least three reasons why firms may prefer to collude on a limited number of choice variables. First, reaching consensus on the coordination of an additional variable complicates the bargaining process and there is plenty of evidence from practice that bargaining issues can significantly disturb the formation of a

\footnotetext{
${ }^{1}$ Contributions that consider competition in price-quantity oligopolies include, for example, Kreps and Scheinkman (1983), Friedman (1988), Dixon (1992) and Tasnádi (2006).

${ }^{2}$ For a recent survey of literature on semicollusion, see Steen and Sørgard (2009).

${ }^{3}$ In this study, whenever we use the term (sales) quota(s), we mean an allocation of quantities or market shares.
} 
cartel. Second, coordinating on more variables may complicate enforcement as more monitoring is required to ensure compliance. Third, more complete cartel contracts leave additional traces of evidence and therefore, ceteris paribus, increase the probability of conviction. In short, if a price cartel and a price-quota cartel are more or less equally successful, then firms are likely not to install an additional quota agreement. For both modes of production, we first analyze optimal price collusion and then evaluate the potential additional value of a quota agreement.

The analysis in this study thus sheds some light on one particular type of cartel heterogeneity: why do some cartels entail an agreement on both prices and quantities, whereas others include only an arrangement on prices? For example, in Carbonless Paper members agreed on the timing and magnitude of price increases for each EEA country. ${ }^{4}$ However, these price-fixing agreements were only sometimes accompanied by quota agreements (e.g., in Spain and France). In Elevators and Escalators members coordinated prices and allocated projects on the basis of a pre-arranged market share scheme. ${ }^{5}$ In particular, a compensation mechanism was adopted to ensure alignment of overall project value with the allocated shares. Yet, in the Netherlands the cartel operated on a project by project basis seemingly without a clear compensation scheme. In Methionine parties fixed minimum and target prices and agreed on concerted price increases. ${ }^{6}$ One of the members proposed a volume control scheme including a compensation mechanism, but sales quotas were never implemented. There are many more real-world examples of price and price-quota cartels. ${ }^{7}$

We find that firms almost always prefer to install a price-quota cartel when production is in advance of sales. However, the reasons for adopting a market sharing scheme in addition to a price-fixing agreement differ. When market demand is relatively elastic, firms will optimally set the monopoly price. In this case, an arrangement on outputs allows firms to deal with both coordination and incentive problems. ${ }^{8}$ The coordination problem concerns the fact that in equilibrium every member should have a sufficiently high level of sales, while ensuring that

\footnotetext{
${ }^{4}$ Case COMP/E-1/36.212 - Carbonless paper.

${ }^{5}$ Case $\mathrm{COMP} / \mathrm{E}-1 / 38.823$ - PO/Elevators and Escalators.

${ }^{6}$ Case C.37.519 - Methionine.

${ }^{7}$ See, for instance, Russo, Schinkel, Günster and Carree (2010). This book provides a complete overview and description of all European cartel cases between 1962 and 2009.

${ }^{8}$ Osborne (1976) identifies four internal problems a cartel may be confronted with. The cartel has to locate the contract surface and choose a point on that surface (the coordination problem). Additionally, it has to detect and deter cheating (the incentive problem).
} 
the market clears. The incentive problem prescribes the cartel to allocate a sufficiently large part of total sales to the smallest members as they appear to have the strongest incentive to defect from the agreement. Therefore, given that the size distribution of members is sufficiently heterogeneous, a price-quota cartel is ceteris paribus more likely than a price-fixing cartel. If market demand is relatively inelastic, then the coordination problem is absent. The reason being that in this case all members optimally produce identical amounts. Yet, sustainability of collusion requires the cartel to set a price below the monopoly price in order to mitigate incentives to defect. In this case, a price-quota cartel is found to be always more profitable than a price-fixing cartel. Specifically, installing an optimal market sharing scheme allows firms to avoid overproduction and to sustain the joint profit maximum.

By contrast, overproduction does not occur in equilibrium when production follows the realization of demand. Moreover, for both price collusion and price-quantity collusion, the profit-maximizing cartel price is the monopoly price. In this case, an additional quota agreement is made solely when a price cartel alone is not sustainable. As with production in advance, the smallest members have the strongest incentive to deviate from the cartel agreement. Hence, sustainability of collusion may require a redistribution of sales from the larger to the smaller cartel participants. Overall, our study suggests that a price-quota cartel is likely to be the rule rather than the exception. An additional quota agreement may not have added value when firms produce to order and are more or less of equal size.

We believe one should be reluctant to bring up evidence from antitrust practice to support general theoretical predictions of cartel behavior like ours. One reason for this is that known cartels differed in many respects. Moreover, they have been operating in a wide variety of industries and had to deal with specific problems. As a result, there are potentially many explanations for observed collusive conduct. Apart from this, relevant information that is required to confidently match a general theoretical framework with a specific cartel case is often lacking. However, in this respect the lysine cartel forms a notable exception. This cartel is one of the most well-documented cases in antitrust history and of particular interest to our study as it had two "lives". ${ }^{9}$ During its first life, members fixed prices but no market sharing scheme was adopted. During its second life, members also agreed on a market share allocation. The market for lysine is characterized by homogeneous products, approximately

\footnotetext{
${ }^{9}$ See, for instance, Connor (2001) and de Roos (2006).
} 
constant unit production costs and relatively inelastic market demand. In this case, our model would predict firms to prefer a price-quota cartel as it allows them to sustain higher prices. This is indeed what happened. That is, the cartel set prices at a significantly higher level during its second life, which was generally more successful. Therefore, there exists some support for our theoretical findings in antitrust practice.

This paper is organized as follows. The next section introduces the model. Section 3 describes the stationary equilibria in markets where production is in advance of sales. The cartel's problem is presented in Section 4. Section 5 provides an analysis of price- and pricequantity collusion when production precedes sales. Section 6 describes the stationary equilibria and provides an analysis of price- and price-quantity collusion when firms produce to order. Section 7 relates our main findings to existing literature that considers cost heterogeneity, private information and demand uncertainty. Moreover, we evaluate the potential impact of strategic inventories. Section 8 concludes. All proofs are relegated to the Appendix.

\section{Model}

We consider a homogeneous good industry in which a fixed and finite set of firms, denoted by $N=\{1, \ldots, n\}$, interact repeatedly over an infinite, discrete time horizon. In this section, we present the assumptions used in analyzing the stage game. Assumptions regarding collusive conduct are introduced in Section 4 .

Firms simultaneously make price and production decisions so as to maximize their expected profit. $A \equiv[0, a] \times[0, b]$ is the common action set and price and quantity choices are respectively denoted by the vectors $\boldsymbol{p} \equiv\left(p_{1}, \ldots, p_{n}\right)$ and $\boldsymbol{q} \equiv\left(q_{1}, \ldots, q_{n}\right)$, where $p_{i} \in$ $[0, a]$ and $q_{i} \in[0, b]$ for all $i \in N$. Define $\boldsymbol{p}_{-\boldsymbol{i}} \equiv\left(p_{1}, \ldots, p_{i-1}, p_{i+1}, \ldots, p_{n}\right)$ and $\boldsymbol{q}_{-\boldsymbol{i}} \equiv$ $\left(q_{1}, \ldots, q_{i-1}, q_{i+1}, \ldots, q_{n}\right)$ as, respectively, the vector of prices and quantities of all firms other than $i$. Firms have identical unit production costs $c \in(0, a)$ and sufficient production capacity available (i.e., there are no capacity constraints).

Market demand is given by $D(p)$, which is a continuous, strictly decreasing and concave function of price in the range $[0, a]$. Additionally, we assume that this function is identically zero on $[a, \infty)$, twice continuously differentiable on $(0, a)$ and $D(0)<b .^{10}$ The monopoly

\footnotetext{
${ }^{10}$ As described below, we assume a proportional demand allocation rule. The reason for assuming $D(0)<b$ is that with such a rule firms potentially have an incentive to produce in excess of $D(0)$. It can be easily verified that there always exists an upper bound on the amount a firm is willing to produce.
} 
price and output are respectively indicated by $p^{m}$ and $q^{m}: D\left(p^{m}\right)+\left(p^{m}-c\right) D^{\prime}\left(p^{m}\right)=0$ and $q^{m}=D\left(p^{m}\right)$.

Demand for the products of firm $i$ is denoted $D_{i}\left(p_{i}, q_{i}, \mathbf{p}_{-\mathbf{i}}, \mathbf{q}_{-\mathbf{i}}\right)$. For any price-quantity configuration, its profit is then given by

$$
\pi_{i}\left(p_{i}, q_{i}, \mathbf{p}_{-\mathbf{i}}, \mathbf{q}_{-\mathbf{i}}\right)=p_{i} D_{i}\left(p_{i}, q_{i}, \mathbf{p}_{-\mathbf{i}}, \mathbf{q}_{-\mathbf{i}}\right)-c q_{i}
$$

Consumers buy first from a supplier charging the lowest price. In specifying firm $i$ 's demand, define $\Delta\left(p_{i}\right) \equiv\left\{j \in N: p_{j}<p_{i}\right\}$ and $\Omega\left(p_{i}\right) \equiv\left\{j \in N: p_{j}=p_{i}\right\}$ as the set of firms that respectively price below and at $p_{i}{ }^{11}$

With production in advance, production takes place before the realization of demand. Thus, a firm learns about prices and production levels of its rivals after it has produced and set the price for its own products. We suppose that in this case demand is established according to a proportional demand allocation rule. If two or more firms charge the same price and total supply exceeds total demand at that price, then sales are assumed proportional to individual levels of production. Firm $i$ 's part of (residual) demand at that price is denoted by $\lambda_{i} \cdot{ }^{12}$

Assumption 1. Assume production in advance. $\lambda_{i}=\frac{q_{i}}{\sum_{j \in \Omega\left(p_{i}\right)} q_{j}}$, for all $i \in N$.

Consequently, suppliers with more products available receive a larger share of market demand, all else unchanged. ${ }^{13}$ Firm $i$ 's demand is then of the following structure:

$$
D_{i}\left(p_{i}, q_{i}, \mathbf{p}_{-\mathbf{i}}, \mathbf{q}_{-\mathbf{i}}\right)=\min \left\{q_{i}, \lambda_{i}\left(D\left(p_{i}\right)-\sum_{k \in \Delta\left(p_{i}\right)} q_{k}\right)^{+}\right\}
$$

\section{Static Nash Equilibrium}

In this section, we characterize the (single-shot) Nash equilibrium of the model described above. If production precedes sales, then there is no pure-strategy Nash equilibrium. However, we will show that there does exist a symmetric mixed-strategy Nash equilibrium for which expected profits amount to zero.

\footnotetext{
${ }^{11}$ Formally, it is $\Delta\left(p_{i}, \mathbf{p}_{-\mathbf{i}}\right)$ and $\Omega\left(p_{i}, \mathbf{p}_{-\mathbf{i}}\right)$. From the context, it will be clear what $\mathbf{p}_{-\mathbf{i}}$ is. We use shorthand notation to stress which value of $p_{i}$ these sets are based on.

${ }^{12}$ We use $\lambda_{i}$ rather than $\lambda_{i}(\mathbf{p}, \mathbf{q})$ as $\mathbf{p}$ and $\mathbf{q}$ follow directly from the context.

${ }^{13}$ Assumption 1 is primarily made for ease of analysis. The findings in this paper are robust against alternative allocation rules as long as the game is symmetric and a firm's share of demand depends positively on its own level of production.
} 
Suppose that production is in advance of sales. The next result establishes that in this case there exists no pure-strategy Nash equilibrium. Yet, we can apply Corollary 5.3 of Reny (1999) to establish the existence of a symmetric mixed-strategy Nash equilibrium.

Theorem 2. Assume production in advance.

(i) There exists no pure-strategy Nash equilibrium.

(ii) There exists a symmetric mixed-strategy Nash equilibrium.

Unfortunately, in the current setting it is difficult if not impossible to determine this mixedstrategy equilibrium explicitly. However, we are able to prove that (expected) equilibrium profits are zero. Below, we provide a generalized version of the analysis presented in Tasnádi (2004), which obtains a similar result for a duopoly.

For the ensuing analysis it can be easily verified that firms will never find it optimal to price below $c$ or above $p^{m}$ while supplying strictly positive quantities. We therefore focus on the case where suppliers choose their actions simultaneously from $S=\left[c, p^{m}\right] \times[0, b]$. In the following, let the space of all (Borel) probability measures on $S$ be given by $P(S)$ and let $\mu_{i} \in P(S)$ denote a mixed strategy of firm $i \in N$. Let $\boldsymbol{\mu}_{-i}$ denote the mixed strategies of all firms other then firm $i$, i.e., $\boldsymbol{\mu}_{-i}=\left(\mu_{1}, \ldots, \mu_{i-1}, \mu_{i+1}, \ldots, \mu_{n}\right)$ and $\boldsymbol{\mu}=\left(\mu_{i}, \boldsymbol{\mu}_{-i}\right)$. The profit of firm $i$, when $\boldsymbol{\mu}$ is the joint strategy, is given by $\pi_{i}(\boldsymbol{\mu})$. A mixed-strategy equilibrium $\boldsymbol{\mu}^{*}$ is then defined by the following condition:

$$
\pi_{i}\left(\mu_{i}, \boldsymbol{\mu}_{-i}^{*}\right) \leq \pi_{i}\left(\mu_{i}^{*}, \boldsymbol{\mu}_{-i}^{*}\right) \text { for all } i \in N \text { and } \mu_{i} \in P(S) .
$$

As we consider a symmetric situation and search for a symmetric equilibrium, we indicate a mixed-strategy Nash equilibrium and corresponding equilibrium profits of a single firm respectively by $\mu$ and $\pi^{*}$ for ease of notation. The support of $\mu$ is denoted by $\operatorname{supp}(\mu)$ and, for any price $p \in\left[c, p^{m}\right], s(p) \subseteq[0, b]$ is the set of quantities $q \in[0, b]$ for which $(p, q) \in \operatorname{supp}(\mu)$. Moreover, let $\mu_{p}$ be the projection of probability measure $\mu$ to the set of prices, i.e., $\mu_{p}(B)=$ $\mu(B \times[0, b])$ for any Borel set $B \subseteq\left[c, p^{m}\right]$. Finally, let $\sup \left\{p \in\left[c, p^{m}\right] \mid \mu_{p}\left(\left[p, p^{m}\right]\right)=1\right\}$ and $\inf \left\{p \in\left[c, p^{m}\right] \mid \mu_{p}([c, p])=1\right\}$ be respectively denoted by $\check{p}$ and $\hat{p}$.

Clearly, if $\check{p}=c$, then $\pi^{*}=0$. In the next two lemmas, we consider the case where $\check{p}>c$.

Lemma 3. If $\check{p}>c$, then $s(\check{p})=\{D(\check{p})\}$ and $\mu_{p}(\{\check{p}\})=0$.

That is, a firm that sets $\check{p}>c$ optimally produces to meet demand at this price. The next 
lemma shows that producing to serve the entire market may also be optimal for prices that are above $\check{p}$.

Lemma 4. If $\check{p}>c$, then there exists a price $p^{\prime} \in\left(\check{p}, p^{m}\right]$ such that $s(p)=\{D(p)\}$ and $\mu_{p}(\{p\})=0$ for all $p \in\left[\check{p}, p^{\prime}\right]$.

Finally, we use this result to establish that the infimum of all prices in the support cannot be strictly above $c$. As a result, all firms make zero expected profits in equilibrium.

Theorem 5. Assume production in advance. $\check{p}=c$ and $\pi^{*}=0$.

\section{Cartel's Problem}

Our next step is to analyze the incentives of firms to establish a particular cartel contract. Towards that end, we consider the infinitely repeated version of the game described in Section 2. In every period $t \in \mathbb{N}$, firms simultaneously make price and production decisions so as to maximize the expected discounted sum of their profit stream, where $\delta \in(0,1)$ is the common discount factor. In each period $t$, the price and quantity choices of all firms up to $t-1$ are common knowledge.

We assume that holding inventories is sufficiently costly so that firms do not find it in their interest to store unsold products.

Assumption 6. Firms do not build inventories.

As will become clear in the ensuing analysis, this assumption is innocuous with production to order as in that case it is never optimal to produce more (or less) than is demanded. However, supply may exceed demand in equilibrium when production is in advance of sale. Although this assumption clearly comes with a price in terms of generality, it is required to keep the analysis tractable. Consequently, our findings related to collusion with production in advance primarily apply to industries selling perishable or fashionable goods. In Section 7.2 below, we elaborate on the theoretical difficulty one encounters when analyzing production in advance in repeated games. In that section, we will also argue that the qualitative nature of most of our findings are robust to the possibility of holding (strategic) inventories.

In the previous section, we found an equilibrium in the stationary setting. If we talk about competition in the infinitely repeated stage game, we refer to a situation in which all 
firms use strategies in which they do not use past-play or timing of current play to decide upon their current actions. Thus, the only subgame perfect equilibrium in competition is the equilibrium in which the (symmetric) stationary outcome prevails every period.

To prevent that from happening, firms can form a collusive agreement. In forming a collusive agreement, firms can choose between two types of cartels: a price cartel and a pricequota cartel. For both cases, we consider an all-inclusive cartel in which all suppliers agree on a common cartel price $p^{c} \in\left(c, p^{m}\right]$. The key difference between the two types of contracts is that with a price cartel firms are free to choose their level of production, whereas a pricequota cartel additionally specifies the level and allocation of outputs. The agreed upon quota in a price-quota cartel for firm $i$ is expressed by $q_{i}^{c}$. We require collusive arrangements to be a subgame perfect equilibrium outcome of the game and it is assumed that firms adopt grim-trigger strategies to sustain collusion. ${ }^{14}$

This results in the following formal definitions of a price cartel strategy and a price-quota cartel strategy. Define $q_{i}(t)$ as the quantity that firm $i \in N$ chooses in period $t$. Let

$$
\mathbf{Q}=\left\{q \in[0, b] \mid \arg \max _{q} \pi_{i}\left(\mathbf{p}^{\mathbf{c}},\left(q, \mathbf{q}_{-\mathbf{i}}\right)\right) \text { for some } \mathbf{q}_{-\mathbf{i}} \in[0, b]^{n-1}\right\}
$$

A strategy profile is a price cartel if there is a price $p^{c} \in\left(0, p^{m}\right]$ and a sequence $q_{i}(1), q_{i}(2), \ldots$ with $q_{i}(t) \in \mathbf{Q}$ for each firm $i$ at all $t$, such that each firm $i$ plays as follows:

- In period 1: set price $p^{c}$ and quantity $q_{i}(1)$;

- In each period $T>1$ : set price $p^{c}$ and quantity $q_{i}(T)$ if all firms have set prices equal to $p^{c}$ at all $t<T$, and play according to the static equilibrium strategy $\mu_{i}^{*}$ otherwise.

A strategy profile is a price-quota cartel if there is a price $p^{c} \in\left(0, p^{m}\right]$ and a quantity $q_{i}^{c} \in[0, b]$ for each firm $i$, such that each firm $i$ plays as follows:

- In period 1: set price $p^{c}$ and quantity $q_{i}^{c}$;

- In each period $T>1$ : set price $p^{c}$ and quantity $q_{i}^{c}$ if all firms $j \in N$ have set prices equal to $p^{c}$ and quantities equal to their individual quantity $q_{j}^{c}$ at all $t<T$, and play according to the static equilibrium strategy $\mu_{i}^{*}$ otherwise.

\footnotetext{
${ }^{14}$ Notice that this is the most severe punishment strategy in our setting as profits in competition are zero. Therefore, if collusion is not sustainable by adopting this strategy, then collusion will not occur in any subgame perfect equilibrium.
} 
To begin, let us focus on a price cartel with a constant output configuration. In this case, the collusive value for firm $i$ is recursively defined by

$$
V_{i}\left(p^{c}, \mathbf{q}\right)=p^{c} D_{i}\left(p^{c}, \mathbf{q}\right)-c q_{i}+\delta V_{i}\left(p^{c}, \mathbf{q}\right)
$$

Rearranging gives,

$$
V_{i}\left(p^{c}, \mathbf{q}\right)=\frac{p^{c} D_{i}\left(p^{c}, \mathbf{q}\right)-c q_{i}}{1-\delta}
$$

As customers buy first from the cheapest supplier, maximum profit that can be earned by defecting from the cartel agreement is obtained by undercutting the cartel price slightly and producing to meet market demand at that price. Notice that this holds for all members of a price- or a price-quota cartel. Consequently, given a particular cartel price $p^{c}$, the optimal defection profit always amounts to $\left(p^{c}-c\right) D\left(p^{c}\right)$. Whether all price-fixing cartels indeed have constant output configurations will be analyzed in the next sections.

As shown in the previous section, competitive behavior yields zero (expected) profits. The incentive compatibility constraint of firm $i$ is therefore given by

$$
\frac{p^{c} D_{i}\left(p^{c}, \mathbf{q}\right)-c q_{i}}{1-\delta} \geq\left(p^{c}-c\right) D\left(p^{c}\right)
$$

or

$$
\delta \geq \delta_{i}^{*}=1-\frac{p^{c} D_{i}\left(p^{c}, \mathbf{q}\right)-c q_{i}}{\left(p^{c}-c\right) D\left(p^{c}\right)}, \text { for all } i \in N
$$

As is well-known, there may exist a plethora of sustainable cartel contracts. Yet, as we require collusion to be subgame perfect and $p^{c}>c$, all these collusive arrangements have in common that total cartel supply will not fall short of market demand. If it did, then there would be at least one firm that would benefit from increasing its production. As a result, firm demand is given by $D_{i}\left(p^{c}, \mathbf{q}\right)=\frac{q_{i}}{\sum_{j \in \Omega\left(p^{c}\right)} q_{j}} D\left(p^{c}\right)$. In turn, this implies that all firms agree to set a cartel price that maximizes total cartel value.

A price cartel thus faces the following constraint optimization problem:

$$
\max _{p} V(p, \mathbf{q})=\max _{p} \frac{p D(p)-c \sum_{j \in N} q_{j}}{1-\delta}
$$

subject to

$$
\begin{aligned}
p D_{i}(p, \mathbf{q})-c q_{i}-(1-\delta)(p-c) D(p) & \geq 0, \text { for all } i \in N \\
\sum_{j \in N} q_{j} & \geq D(p) .
\end{aligned}
$$


The key question is then if and how firms can benefit from an additional quota agreement. In the following, we analyze this issue in more detail for markets that are respectively characterized by production in advance (Section 5) and production to order (Section 6).

\section{Collusion with Production in Advance}

\subsection{Price Cartel}

Suppose that the cartel prices at $p^{c} \in\left(c, p^{m}\right]$ and that production is in advance of sale. In the following, we start by considering a price cartel and then analyze if and under which conditions firms would prefer to establish a price-quota cartel instead. As a price cartel does not include an agreement on sales, all members are unrestricted in their choice of output. That is to say, every firm can individually decide on its production level without having to fear retaliation from its rivals. Consequently, a cartel member produces to maximize current profit given the output choices of its fellow members. The production level that maximizes firm $i$ 's current profit, given the output choices of the other participants, is denoted $q_{i}^{*}\left(p^{c}, \mathbf{q}_{-\mathbf{i}}\right)$.

The next result specifies the optimal production decision at a given cartel price.

Lemma 7. Assume production in advance and a price cartel with common cartel price $p^{c} \in\left(c, p^{m}\right]$. For all $i \in N$, the best reply production choice $q_{i}^{*}\left(p^{c}, \mathbf{q}_{-\mathbf{i}}\right)$ is given by:

$q_{i}^{*}\left(p^{c}, \mathbf{q}_{-\mathbf{i}}\right)= \begin{cases}D\left(p^{c}\right)-\sum_{j \in N \backslash\{i\}} q_{j} & \text { if } \sum_{j \in N \backslash\{i\}} q_{j} \leq D\left(p^{c}\right) c / p^{c} \\ \sqrt{\frac{p^{c} D\left(p^{c}\right)\left(\sum_{j \in N \backslash\{i\}} q_{j}\right)}{c}}-\sum_{j \in N \backslash\{i\}} q_{j} & \text { if } D\left(p^{c}\right) c / p^{c}<\sum_{j \in N \backslash\{i\}} q_{j} \leq D\left(p^{c}\right) p^{c} / c \\ 0 & \text { if } \sum_{j \in N \backslash\{i\}} q_{j}>D\left(p^{c}\right) p^{c} / c .\end{cases}$

Observe that the first in combination with the second or the third optimal response cannot occur in equilibrium. Likewise, we can exclude the possibility that in equilibrium some firms adopt the middle best response and some firms produce nothing. To see this, notice that in this case it must hold that $\sum_{i \in N} q_{i}=\sqrt{\frac{p^{c} D\left(p^{c}\right)\left(\sum_{j \in N \backslash\{i\}} q_{j}\right)}{c}}$ and $\sum_{j \in N \backslash\{i\}} q_{j} \leq D\left(p^{c}\right) p^{c} / c$. This implies $\sum_{i \in N} q_{i} \leq \sqrt{\frac{p^{c} D\left(p^{c}\right)\left(D\left(p^{c}\right) p^{c} / c\right)}{c}}=D\left(p^{c}\right) p^{c} / c$. If a firm would produce nothing, then $\sum_{j \in N \backslash\{i\}} q_{j} \leq D\left(p^{c}\right) p^{c} / c$. Yet, zero production is only a best response when $\sum_{j \in N \backslash\{i\}} q_{j}>$ $D\left(p^{c}\right) p^{c} / c$; a contradiction. This leaves two possibilities that can occur in equilibrium. Either, all firms produce according to the first best response (i.e., $\sum_{i \in N} q_{i}=D\left(p^{c}\right)$ ), or all firms set their outputs such that $\sum_{i \in N} q_{i}=\sqrt{\frac{p^{c} D\left(p^{c}\right)\left(\sum_{j \in N \backslash\{i\}} q_{j}\right)}{c}}$. In the latter case, total supply exceeds market demand.

The next result shows that, in the event of overproduction, all firms produce the same 
quantity.

Lemma 8. If $q_{v}^{*}\left(p^{c}, \mathbf{q}_{-\mathbf{v}}\right)=\sqrt{\frac{p^{c} D\left(p^{c}\right)\left(\sum_{j \in N \backslash\{v\}} q_{j}\right)}{c}}-\sum_{j \in N \backslash\{v\}} q_{j}$ and $q_{w}^{*}\left(p^{c}, \mathbf{q}_{-\mathbf{w}}\right)=\sqrt{\frac{p^{c} D\left(p^{c}\right)\left(\sum_{j \in N \backslash\{w\}} q_{j}\right)}{c}}-$ $\sum_{j \in N \backslash\{w\}} q_{j}$, then $q_{v}^{*}\left(p^{c}, \mathbf{q}_{-\mathbf{v}}\right)=q_{w}^{*}\left(p^{c}, \mathbf{q}_{-\mathbf{w}}\right)$ for all $v, w \in N$.

The previous two findings are useful in characterizing the set of subgame perfect equilibria. It appears that equilibrium production decisions in part depend on the level of the cartel price.

Theorem 9. Assume production in advance. If a price cartel $\left(p^{c}, \mathbf{q}^{*}\right)$ is a subgame perfect Nash equilibrium, then for all $i \in N$,

(i) $p^{c} \leq \frac{c n}{n-1}, q_{i}^{*}\left(p^{c}, \mathbf{q}_{-\mathbf{i}}\right)=D\left(p^{c}\right)-\sum_{j \in N \backslash\{i\}} q_{j}^{*}\left(p^{c}, \mathbf{q}_{-\mathbf{j}}\right)$ and $q_{i}^{*}\left(p^{c}, \mathbf{q}_{-\mathbf{i}}\right) \geq\left(\frac{p^{c}-c}{p^{c}}\right) D\left(p^{c}\right)$, (ii) $p^{c}>\frac{c n}{n-1}$ and $q_{i}^{*}\left(p^{c}, \mathbf{q}_{-\mathbf{i}}\right)=\frac{(n-1) p^{c} D\left(p^{c}\right)}{c n^{2}}$.

Thus, in equilibrium, the collusive value for firm $i$ is given by

$$
V_{i}\left(p^{c}, \mathbf{q}^{*}\right)= \begin{cases}\frac{\left(p^{c}-c\right)\left(D\left(p^{c}\right)-\sum_{j \in N \backslash\{i\}} q_{j}^{*}\left(p^{c}, \mathbf{q}_{-\mathbf{j}}\right)\right)}{1-\delta} & \text { for } p^{c} \leq \frac{c n}{n-1} \text { and } q_{i}^{*}\left(p^{c}, \mathbf{q}_{-\mathbf{i}}\right) \geq \\ & \left(\frac{p^{c}-c}{p^{c}}\right) D\left(p^{c}\right) \text { for all } i \in N, \text { or } \\ \frac{p^{c} D\left(p^{c}\right)}{(1-\delta) n^{2}} & \text { for } p^{c}>\frac{c n}{n-1} \text { and } q_{i}^{*}\left(p^{c}, \mathbf{q}_{-\mathbf{i}}\right)= \\ & \frac{(n-1) p^{c} D\left(p^{c}\right)}{c n^{2}} \text { for all } i \in N .\end{cases}
$$

The next issue is to find the price that maximizes the total cartel value. Following Theorem 9 , we can distinguish two cases. First, if the cartel sets a price $p \leq \frac{c n}{n-1}$, then $q_{i}^{*}\left(p, \mathbf{q}_{-\mathbf{i}}\right)=$ $D(p)-\sum_{j \in N \backslash\{i\}} q_{j}^{*}\left(p, \mathbf{q}_{-\mathbf{j}}\right)$ for all $i \in N$. Therefore, the incentive compatibility constraint as given by (5) reduces to

$$
\delta \geq \hat{\delta_{i}^{*}}=1-\frac{q_{i}^{*}\left(p, \mathbf{q}_{-\mathbf{i}}\right)}{\sum_{j \in N} q_{j}^{*}\left(p, \mathbf{q}_{-\mathbf{j}}\right)}, \text { for all } i \in N,
$$

which does not directly depend on the cartel price. As a result, if $p^{m} \leq \frac{c n}{n-1}$, then the cartel optimally sets the monopoly price. Note that, since $\max _{i \in N} \hat{\delta_{i}^{*}} \geq 1-\frac{1}{n}$, this can only occur if $\delta \geq 1-\frac{1}{n}$.

Second, all cartel participants optimally produce $q^{*}(p)=\frac{(n-1) p D(p)}{c n^{2}}$ at any price $p>\frac{c n}{n-1}$. In this case, the incentive compatibility constraint as given by (5) is therefore given by

$$
\delta \geq \tilde{\delta^{*}}(p)=1-\frac{p}{n^{2}(p-c)},
$$

which is the same for all firms and directly depends on price. In fact, $\tilde{\delta}^{*}(p)$ is an increasing and concave function of $p$ and, since $\tilde{\delta^{*}}\left(\frac{c n}{n-1}\right)=1-\frac{1}{n}$, also this incentive compatibility constraint can only hold as long as $\delta \geq 1-\frac{1}{n}$. 
Given that the cartel price exceeds $\frac{c n}{n-1}$, define $p^{*}$ as the unconstrained solution of the cartel problem:

$$
\frac{d V\left(p, \mathbf{q}^{*}(p)\right)}{d p}=\frac{p D^{\prime}(p)+D(p)}{(1-\delta) n^{2}}=0
$$

Thus, $p^{*}$ solves $p^{*} D^{\prime}\left(p^{*}\right)+D\left(p^{*}\right)=0$ and therefore $p^{m}>p^{*}$. Additionally, define $\tilde{p}$ as the constrained solution, i.e., $\delta=1-\frac{\tilde{p}}{n^{2}(\tilde{p}-c)}$.

Using the foregoing analysis, the next Proposition summarizes the optimal pricing decision of a price-fixing cartel.

Proposition 10. Assume production in advance and $\delta \geq 1-\frac{1}{n}$. The optimal cartel price $p^{c}$ is specified as follows:

1. Suppose $p^{m} \leq \frac{c n}{n-1}$.

(a) If $\delta \geq \hat{\delta}_{i}^{*}$ for all $i \in N$, then $p^{c}=p^{m}$.

2. Suppose $p^{m}>\frac{c n}{n-1}$.

(a) If $p^{*}<\frac{c n}{n-1}$, then $p^{c}=\frac{c n}{n-1}$.

(b) If $\delta<\tilde{\delta^{*}}\left(p^{*}\right)$ and $p^{*} \geq \frac{c n}{n-1}$, then $p^{c}=\tilde{p}$.

(c) If $\delta \geq \tilde{\delta}^{*}\left(p^{*}\right)$ and $p^{*} \geq \frac{c n}{n-1}$, then $p^{c}=p^{*}$.

These four scenarios are illustrated in Figure 1 below (where $\left.\hat{\delta} \equiv \max \left\{\hat{\delta_{1}^{*}}, \ldots, \hat{\delta_{n}^{*}}\right\}\right)$.

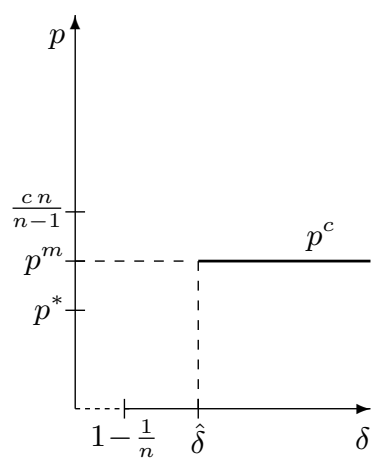

(1a)

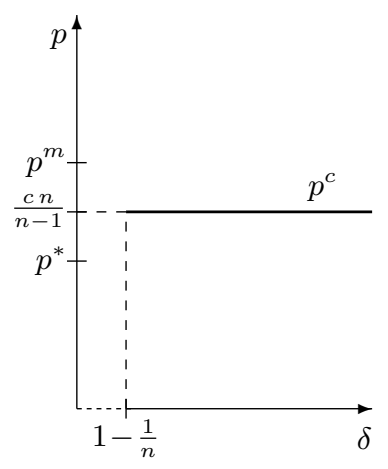

(2a)

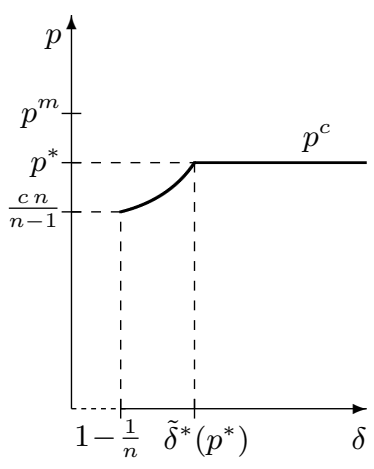

$(2 \mathrm{~b}-\mathrm{c})$

Figure 1: Optimal pricing decision of a price cartel when production precedes sales. 


\subsection{Price-Quota Cartel}

Above, we have characterized the optimal collusive strategy for a price-fixing cartel. The remaining issue is to analyze if and how suppliers could benefit from an additional quota agreement. In the following, we show that there are at least three arguments in favor of a price-quota cartel when production is in advance of sales.

First, if $p^{c} \leq \frac{c n}{n-1}$, then by Theorem 9 production levels must be such that $q_{i}^{*}\left(p^{c}, \mathbf{q}_{-\mathbf{i}}\right)=$ $D\left(p^{c}\right)-\sum_{j \in N \backslash\{i\}} q_{j}^{*}$ and $q_{i}^{*}\left(p^{c}, \mathbf{q}_{-\mathbf{i}}\right) \geq\left(\frac{p^{c}-c}{p^{c}}\right) D\left(p^{c}\right)$. Thus, the market should clear while ensuring that every cartel participant has a sufficiently high level of sales. Combining both these requirements yields the following rather striking result.

Corollary 11. Assume production in advance and $p^{c} \leq \frac{c n}{n-1}$. The market share of every cartel member must (weakly) exceed the Lerner index.

A price cartel therefore faces a coordination problem when it prices at $p^{c}<\frac{c n}{n-1}$ and this holds true for $p^{m}<\frac{c n}{n-1} \cdot{ }^{15}$ As in this case there seems to be no natural division of outputs, an explicit arrangement on market shares may be required to solve this coordination problem.

In addition, a quota agreement may also be needed to solve the incentive problem when $p^{m} \leq \frac{c n}{n-1}$. Observe that the minimum critical discount factor is always weakly larger than $1-\frac{1}{n}$, which is obtained with an equal division of sales. We therefore conclude that there exists no viable cartel when $\delta<1-\frac{1}{n}$. Yet, given that $\delta \geq 1-\frac{1}{n}$, viability of a cartel may still require a market sharing scheme to prevent the smallest member(s) from leaving the ring.

Theorem 12. Assume production in advance, $\delta \geq 1-\frac{1}{n}$ and $p^{m} \leq \frac{c n}{n-1}$.

(i) If $1-\frac{1}{n} \leq \delta<1-\frac{q_{i}^{*}\left(p^{c}, \mathbf{q}_{-\mathbf{i}}\right)}{\sum_{j \in N} q_{j}^{*}\left(p^{c}, \mathbf{q}_{-\mathbf{j}}\right)}$ for some firm $i \in N$, then there exists only a viable price-quota cartel, and

(ii) If $1-\frac{q_{i}^{*}\left(p^{c}, \mathbf{q}_{-\mathbf{i}}\right)}{\sum_{j \in N} q_{j}^{*}\left(p^{c}, \mathbf{q}_{-\mathbf{j}}\right)} \leq \delta$ for all $i \in N$, then there exists both a viable price cartel and a price-quota cartel.

Finally, if $p^{m}>\frac{c n}{n-1}$, then Proposition 10 reveals that a price-fixing cartel is feasible. Moreover, in this case firms have no coordination problem as they optimally produce the same amount of products at any cartel price $p^{c} \geq \frac{c n}{n-1}$. Here, the only reason for suppliers to establish a price-quota cartel is that it generates more profits than a price cartel. In

\footnotetext{
${ }^{15}$ This coordination problem is absent for $p^{c}=\frac{c n}{n-1}$ as then all members find it optimal to produce the same amount of products.
} 
particular, we know by Proposition 10 that the profit-maximizing price of a price cartel is below the monopoly price. Implementing an optimal quota scheme allows firms to avoid excessive production and to sustain the monopoly price, thereby increasing the collusive value.

Theorem 13. Assume production in advance, $\delta \geq 1-\frac{1}{n}$ and $p^{m}>\frac{c n}{n-1}$. There exists a price-quota cartel for which $V_{i}\left(p^{c}, \mathbf{q}^{\mathbf{c}}\right)>V_{i}\left(p^{c}, \mathbf{q}^{*}\left(p^{c}\right)\right)$ for all $i \in N$. An optimal price-quota cartel contract has all firms pricing at $p^{m}$ and a total production of $D\left(p^{m}\right)$.

In conclusion, if market demand is sufficiently elastic, then a quota agreement may be required to solve a coordination and an incentive problem. As to the latter, the price-quota cartel ceteris paribus leads to a convergence of market shares. By contrast, when market demand is sufficiently inelastic, the sole reason for establishing an additional quota agreement is that it allows the cartel to sustain a higher price while reducing costs due to overproduction. As $\frac{c n}{n-1}$ is decreasing in $n$, the latter situation is more likely the larger the number of firms in the industry. Contrary to conventional wisdom, this implies that the coordination problem may be more pronounced the fewer the number of cartel participants, all else equal.

\section{Production to Order}

Let us now consider the case where production is in response to specific buyer requests. The fundamental difference with the previous analysis lies in the way in which firms' demand is determined. With production to order, producers simultaneously choose a price and a quantity they are willing to supply at that price. Unlike with production in advance, there is no commitment to a particular production level ex ante as demand is realized before actual production takes place. Consequently, the allocation of customers when two or more firms charge the same price does not depend on produced quantities. In this case, we use $\alpha$ to describe a firm's share of market demand. Specifically, if all suppliers charge the same price and total supply does not fall short of market demand at that price, then $\alpha_{i}$ is the (exogenously given) market share of firm $i$.

Firm $i$ 's demand, absent any quota agreement, is therefore of the following structure:

$$
D_{i}\left(p_{i}, \mathbf{p}_{-\mathbf{i}}\right)= \begin{cases}\frac{\alpha_{i}}{\sum_{j \in \Omega\left(p_{i}\right)} \alpha_{j}} & \text { if } p_{i} \leq p_{j} \text { for all } j \in N \backslash\{i\} \\ 0 & \text { otherwise. }\end{cases}
$$

Firm $i$ 's profits are then given by

$$
\pi_{i}\left(p_{i}, \mathbf{p}_{-\mathbf{i}}\right)=\left(p_{i}-c\right) D_{i}\left(p_{i}, \mathbf{p}_{-\mathbf{i}}\right)
$$




\subsection{Static Nash Equilibrium}

In this setting, firms de facto compete in price to attract orders. As there are no capacity constraints, we obtain the well-known result that firms optimally price at marginal cost and produce to meet demand at that price. That is, akin to the Bertrand paradox, there exists a pure-strategy Nash equilibrium in which (at least two) firms price at $c$. There is no other Nash equilibrium in which one or more suppliers make a positive profit. Consequently, stationary profits are zero when firms produce to order. This provides a strong incentive for firms to engage in a cartel. But what (type of) cartel contract is most likely to be formed? It is this issue that we address in the next subsection.

\subsection{Collusion}

If firms form a price cartel by fixing prices at $p^{c}>c$, then firm $i$ faces a demand of $\alpha_{i} D\left(p^{c}\right)$. As $p^{c}>c$, it is an optimal strategy for every member to produce up to its demand. Thus, the collusive value for firm $i$ is recursively defined by

$$
V_{i}\left(p^{c}\right)=\left(p^{c}-c\right) \alpha_{i} D\left(p^{c}\right)+\delta V_{i}\left(p^{c}\right)
$$

which is equivalent to

$$
V_{i}\left(p^{c}\right)=\frac{\left(p^{c}-c\right) \alpha_{i} D\left(p^{c}\right)}{1-\delta}
$$

As with production in advance, optimal defection profits amount to $\left(p^{c}-c\right) D\left(p^{c}\right)$. Cartel members therefore face the following incentive compatibility constraint:

$$
\delta \geq \delta_{i}^{*}=1-\alpha_{i} \text {, for all } i \in N \text {. }
$$

As before, sustainability of collusion requires $\delta \geq 1-\frac{1}{n}$, which is obtained with an equal division of sales. Yet, unlike with production in advance, a price cartel will not face a coordination problem. Also, the incentive constraint is independent of the elasticity of market demand. In fact, given that $\delta \geq 1-\frac{1}{n}$, whether or not price collusion is viable solely depends on the size distribution of cartel participants. Specifically, feasibility of collusion requires the market share of the smallest cartel member(s) to be sufficiently large. As the critical discount factor is independent of the cartel price, the cartel will optimally set the monopoly price, i.e., $p^{c}=p^{m}$. The next result therefore closely resembles Theorem 12 above. 
Theorem 14. Assume production to order and $\delta \geq 1-\frac{1}{n}$.

(i) If $1-\frac{1}{n} \leq \delta<1-\frac{\alpha_{i}}{\sum_{j \in N} \alpha_{j}}$ for some firm $i \in N$, then there exists only a viable price-quota cartel, and

(ii) If $1-\frac{\alpha_{i}}{\sum_{j \in N} \alpha_{j}} \leq \delta$ for all $i \in N$, then there exists both a viable price cartel and a price-quota cartel.

When firms produce to order, a price cartel and a price-quota cartel are equally profitable as in both cases the cartel mimics a multi-plant monopolist. Consequently, the only reason for firms to adopt a market sharing scheme is that without such an arrangement collusion may not be sustainable. In particular, the cartel may have to agree on a redistribution of sales from the larger to the smaller members. ${ }^{16}$ There are several ways in which firms can arrange a more equal division of sales. For example, larger firms may simply refuse to serve part of their demand so as to increase the residual demand for the products of smaller members. Alternatively, the cartel may adopt a more sophisticated system of end-of-the-year buy backs to ensure that every member meets its pre-arranged output level. It is noteworthy that such agreements have been observed several times in antitrust practice. ${ }^{17}$

\section{Discussion}

The above analysis has been conducted under several assumptions, some of which we believe warrant some discussion. In the following, we relate our work to literature that considers settings with cost heterogeneity, demand uncertainty and private information. Moreover, we discuss the extent to which our results are robust to the possibility of holding inventories.

\subsection{Cost Asymmetries, Demand Uncertainty and Private Information}

By studying collusion in a price-quantity oligopoly, our analysis sheds some light on what type of cartel we may expect in particular type of industries. Our findings suggest that we often may expect firms to agree on both prices and quantities, albeit for various reasons. We have derived results in a setting where both prices and quantities are public information and firms have accurate knowledge about cost and demand functions. Clearly, relaxing one

\footnotetext{
${ }^{16}$ In this paper, we derive results for a given cartel size. Alternatively, when cartel formation is assumed endogenous, it may be more optimal for the larger firms to form a less than all-inclusive cartel leaving out the smaller firms. This possibility is analyzed in Bos and Harrington (2010).

${ }^{17}$ See, for example, Harrington (2006).
} 
or more of these assumptions may provide alternative explanations for when to expect firms to establish a price-quota cartel. Existing literature has offered various rationales for full collusion in the presence of cost and demand shocks and in case strategic choice variables are private information. Here, we briefly discuss this related literature.

Let us first discuss the possibility of cost heterogeneity. In our setting, differences in firm size are unrelated to differences in unit costs. Consequently, a market-sharing scheme when implemented is also not driven by efficiency considerations. This is unlikely to hold in general as differences in unit costs may give rise to asymmetric incentive schemes. For instance, one may conjecture a cartel to allocate a relatively large market share to more efficient members as these have more to gain from defection and less to fear from retaliation. ${ }^{18}$ In this respect, Harrington (1991) shows that whether or not an optimal market sharing rule is sensitive to cost differences in part depends on the level of the discount factor. Specifically, the market sharing rule is independent of firms' unit costs when the discount factor is relatively low, but not when firms are sufficiently patient.

The potential impact of cost heterogeneity on collusion has also been analyzed in a setting of fluctuating demand conditions. Choi, Menezes and Tressler (1985), for example, consider a static framework in which firms negotiate price and market shares to establish an efficient cartel agreement. Assuming cost heterogeneity and demand uncertainty, the prediction is that the cartel arrangement includes averaging of unit production costs. Moreover, this study predicts a convergence of market shares when market demand declines. The reason being that the small firms (i.e., high cost firms) must earn sufficient profits for the cartel to remain effective. Alternatively, firms may engage in involuntary periodic price wars to sustain collusion. Indeed, as Green and Porter (1984) predicts, a temporary breakdown in prices may be required to maintain a collusive scheme when demand conditions are fluctuating and firms' quantities are private information.

Market share schemes potentially also play an important role when production costs are not publicly known. As Athey and Bagwell (2001) points out, market share agreements may allow producers to collude perfectly when they experience privately observed cost shocks in each period. By exchanging future market share favors efficiently, first-best profits can be attained when firms are sufficiently patient. Such a rather sophisticated price-quota cartel

\footnotetext{
${ }^{18}$ Note that sustainability of collusion with differences in unit costs may also require a more equal division of sales, because efficient firms have more to gain from a cartel.
} 
is preferred as it induces a high cost firm to reveal its identity, thereby allowing the cartel to produce efficiently. In a comparable setting, Athey, Bagwell and Sanchirico (2004) shows that optimal collusion may induce firms to fix both prices and market shares. In particular, this implies that the cartel foregoes productive efficiency as low cost firms produce relatively too little and high costs firms produce relatively too much. Yet, it is also found that when firms are sufficiently impatient, effectiveness of collusion may require low cost firms to set a lower price in order to gain more market share.

A couple of recent studies has considered collusion in a setting where prices or quantities are private information. Harrington and Skrzypacz (2007) shows that when prices are not publicly observable (but firms' quantities are), then the mere threat of (symmetric) price wars may be insufficient to sustain collusion. Yet, collusion may be sustainable through an asymmetric punishment scheme that prescribes firms that sold in excess of their quota to compensate those members that sold under quota. In a similar fashion, Harrington and Skrzypacz (2010) shows that firms with high sales may have an incentive to compensate members with low sales to sustain collusion in an environment where both prices and quantities are private information. That firms do not need much information to collude effectively has been recently confirmed by Hörner and Jamison (2007). This study finds that firms require hardly any information to collude almost perfectly. However, to obtain this result, firms need to agree on both prices and market shares.

The studies mentioned above reveal that there are distinct possibilities for price-fixing firms to benefit from a market sharing scheme. In this respect, our findings are complementary and suggest that price-quota cartels are likely to be the rule. Put differently, even in a world where cost and demand are known and stable and actions are publicly observable, firms often benefit from a market sharing agreement.

\subsection{Strategic Inventories}

The analysis in this paper has been conducted under the assumption that firms do not build inventories (Assumption 6). We now evaluate the extent to which our main findings are robust to the possibility that suppliers store unsold products. To begin, a firm that produces to order will never find it in its interest to hold inventories in our setting. Due to discounting, it is not optimal to produce in excess of demand in the current period with the aim to sell 
these units in future periods. Moreover, as production follows the realization of demand, overproduction does not occur "by accident". Thus, even absent inventory costs, allowing for inventories would not affect our results regarding production to order.

This story is somewhat more complicated when production precedes sales. Let us first evaluate the potential impact of inventories on the nature of competition. Observe that a firm can still guarantee itself non-negative profits by charging a sufficiently high price or by producing nothing. Yet, in contrast to Theorem 5, expected competitive profits may no longer be zero. To see this, suppose that suppliers do not price below $c$ and let $x_{i}>0$ be the inventory of firm $i \in N$. Now suppose that firm $i$ produces nothing and sets $p_{i}=c$. In this case, its profit is given by $c D_{i}\left(c, x_{i}, \mathbf{p}_{-\mathbf{i}}, \mathbf{q}_{-\mathbf{i}}\right)$, where $D_{i}\left(c, x_{i}, \mathbf{p}_{-\mathbf{i}}, \mathbf{q}_{-\mathbf{i}}\right)=\min \left\{x_{i}, \frac{x_{i}}{\sum_{j \in \Omega(c)} q_{j}} D(c)\right\}$. Given that its rivals do not price below $c$ (a possibility that cannot be ruled out here), it holds that $D_{i}\left(c, x_{i}, \mathbf{p}_{-\mathbf{i}}, \mathbf{q}_{-\mathbf{i}}\right)>0$. As a result, holding inventories potentially allows firms to make positive profits in competition. This renders the analysis intractable as the static Nash equilibrium could not even be determined explicitly absent inventories. ${ }^{19}$

Yet, as this paper is primarily concerned with collusion, the more relevant issue is how inventories could affect our predictions of cartel behavior. As suppliers can guarantee themselves a non-negative profit stream in competition, allowing for inventories potentially affects the expected punishment in response to defection. Specifically, the possibility of holding inventories may yield a less severe threat point and therefore tighten the incentive compatibility constraint, all else equal. This clearly lowers the likelihood of collusion, but does not alter the qualitative nature of our findings. The same holds for the optimal deviating strategy, because profits of defection are still maximized by slightly undercutting the cartel price and supply to meet market demand at that price. That is to say, as firms in our model face no capacity constraint there is no gain from building inventories with the aim to increase deviating profits. ${ }^{20}$ This leaves the potential impact of inventories on firm behavior under the cartel regime. As in the analysis above, we distinguish two cases on the basis of the elasticity of market demand.

\footnotetext{
${ }^{19}$ To solve this problem, one needs to be able to characterize optimal intertemporal production policies. As Van den Berg, Bos, Herings and Peters (2011) clearly illustrates, such an analysis is everything but trivial even when firms make intertemporal supply decisions without production.

${ }^{20}$ If firms are capacity constrained, then inventories may play a vital role in sustaining collusion. In such a setting, inventories allow for an instant and significant increase in sales following a deviation, thereby ensuring that the punishment is effective. See Rotemberg and Saloner (1989) for an analysis and discussion of this possibility.
} 
Suppose $p^{c}>\frac{c n}{n-1}$. In this case, all members of the price cartel optimally supply $\frac{(n-1) p^{c} D\left(p^{c}\right)}{c n^{2}}$ in the first period, whereas firm demand is $\frac{1}{n} D\left(p^{c}\right)$. As a result, all participants are left with an inventory of $x=\frac{(n-1) p^{c} D\left(p^{c}\right)-c n D\left(p^{c}\right)}{c n^{2}}>0$. In the second period, every member thus maximizes the following profit function

$$
\max _{q_{i}} \pi\left(p^{c}, \mathbf{q}\right)=\frac{q_{i}+x}{\sum_{j \in N}\left(q_{j}+x\right)} p^{c} D\left(p^{c}\right)-c q_{i} .
$$

This function is concave in $q_{i}$ and reaches its maximum at

$$
q_{i}^{*}=\sqrt{\frac{p^{c} D\left(p^{c}\right)\left((n-1) x+\sum_{j \in N \backslash\{i\}} q_{j}\right)}{c}}-n x-\sum_{j \in N \backslash\{i\}} q_{j} \text {, for all } i \in N .
$$

It can be easily verified that (10) implies $q_{i}^{*}=q_{j}^{*}$ for all $i, j \in N$ and

$$
q_{i}^{*}+x=\frac{p^{c} D\left(p^{c}\right)(n-1)}{c n^{2}}, \text { for all } i \in N
$$

Therefore, if firms are allowed to hold inventories and $p^{c}>\frac{c n}{n-1}$, then they still find it optimal to supply identical amounts. Specifically, the possibility of storing unsold products gives members a recurring additional profit compared to the situation without inventories. Moreover, deviating profits are higher as part of the products have been produced in previous periods. Therefore, if $p^{c}>\frac{c n}{n-1}$, then the possibility of holding inventories affects collusive and deviating profits and potentially makes the threat point less severe. We do not know which of these effects dominates. Yet, as the situation is symmetric, the qualitative nature of our findings remains unaltered.

Finally, suppose $p^{c} \leq \frac{c n}{n-1}$. In this case, members of the price cartel do not produce in excess of demand. Therefore, allowing for inventories will not affect collusive and deviating profits. The only thing that might change are the profits during the punishment phase, which in fact could materially affect our results. To see this, suppose that a firm defects from the cartel arrangement. The deviator has no inventory left, but the loyal members do as they are suddenly confronted with zero sales in the period of defection. As a consequence, the situation is asymmetric after the period of defection. As explained above, expected competitive profits weakly exceed zero. Therefore, collusion is less likely to be sustainable, all else equal. However, the more pronounced problem is that we do not know which of the members has the highest incentive to defect. It could be the largest firm. On the one hand, this firm has less to gain by defecting but, on the other hand, it faces a less severe punishment as its fellow members 
have less inventory. By contrast, it could be the smallest member. This firm has most to gain from deviating, but at the same time its expected punishment is more severe as the other firms have more inventory left.

In conclusion, firms have no incentive to build inventories for strategic reasons in our setting. Nevertheless, producing in excess of demand can be rationalized when production is in advance of sale. We have argued that storing these unsold products will not alter the qualitative nature of our findings when market demand is sufficiently inelastic. The reason is that the situation remains symmetric in this case. Allowing for inventories could materially affect our findings when market demand is relatively elastic, because it may create asymmetric cartel incentive schemes. It is noteworthy, however, that an additional market sharing agreement could solve this problem. That is to say, the maximum critical discount factor is still minimized with an equal division of sales. Therefore, our prediction that a price-quota cartel is preferred to a price-fixing cartel when it leads to a more equal division of sales is robust to the possibility of holding inventories, all else unchanged.

\section{Concluding Remarks}

Why do we observe various types of cartel contracts in antitrust practice? In this study, we have sought to shed some light on one specific sort of cartel heterogeneity: price versus price-quota cartels. Existing literature has shown that an additional agreement on production levels may be needed to overcome incentive problems that arise due to imperfect information and demand uncertainty. This paper provides an alternative explanation. In the context of an infinitely repeated game with complete information, sustainability of collusion may still require an agreement on sales levels. Specifically, the market share of the smallest cartel member must be sufficiently large, which may induce firms to arrange a more equal division of outputs. This holds when firms produce to order and when production is in advance of sale and market demand is sufficiently elastic. As to the latter, an arrangement on outputs may additionally help firms to solve a coordination problem. Moreover, with production in advance, establishing an output ceiling is always profitable when market demand is sufficiently inelastic. Consequently, there are several rationales for the existence of both price and pricequota cartels, even in a world of certainty and perfect information.

These results have potentially important implications in light of antitrust enforcement. 
For instance, industries with price increases in conjunction with a decline in sales volume and converging market shares should, ceteris paribus, be considered suspect of anti-competitive practices. Also, refusals to deal at relatively high prices in combination with relatively low capacity utilization may indicate the presence of a cartel. However, such observations should always be judged while taking account of the idiosyncrasies of a particular industry. Indeed, our analysis suggests that market characteristics may play a vital role in the design of a cartel contract. In particular, knowing when and where to expect a price-quota cartel is likely to increase the effectiveness of antitrust enforcement as the chance of discovering physical evidence is higher, all else equal. The reason being that, unlike with price collusion, it is difficult to see how firms can coordinate their sales levels without communicating explicitly. Yet, to what extent our theoretical findings are helpful in detecting cartels is ultimately an empirical question. We leave this issue for future research. 


\section{Appendix: Proofs}

\section{Proof of Theorem 2.}

(i) If all firms price above $c$, then there is at least one firm that finds it optimal to undercut the lowest price slightly and serve market demand at that price. Therefore, let $M=\left\{i \in N \mid p_{i}=c\right\}$ the set of firms that price at $c$, where $|M| \geq 1$. In this case, for all $i \in M, q_{i}>D_{i}\left(c, q_{i}, \mathbf{p}_{-\mathbf{i}}, \mathbf{q}_{-\mathbf{i}}\right)$ gives $\pi_{i}<0$, whereas $q_{i}=D_{i}\left(c, q_{i}, \mathbf{p}_{-\mathbf{i}}, \mathbf{q}_{-\mathbf{i}}\right)$ gives $\pi_{i}=0$. Thus, a firm pricing at $c$ will not produce in excess of its demand. This implies that there exists a firm $j \in M$ for which it holds that $D(c)-\sum_{i \in M \backslash\{j\}} q_{i}>0$. As a result, this firm $j$ can do better by charging a higher price and produce to meet its residual demand at that price. Hence, there exists no pure-strategy Nash equilibrium.

(ii) In our setting, the strategy space $A$ is compact and the game is symmetric. Therefore we can apply Corollary 5.3 of Reny (1999). According to this corollary, there exists a symmetric mixed strategy equilibrium in our game if its mixed extension is diagonally payoff secure and each $\pi_{i}(\mu, \ldots, \mu)$ is upper semicontinuous as a function of $\mu$ on $P(A)$. Here, $P(A)$ is the space of all (Borel) probability measures on $A$ endowed with the weak topology.

- Upper semicontinuity: To proof that each $\pi_{i}(\mu, \ldots, \mu)$ is upper semicontinuous as a function of $\mu$ on $P(A)$, we have to show that $\lim \sup \pi_{i}\left(\mu^{t}, \ldots, \mu^{t}\right) \leq \pi_{i}(\mu, \ldots, \mu)$ whenever $\lim _{t \rightarrow \infty} \mu^{t}=\mu$. This is equivalent to showing that every converging subsequence has a limit that is smaller or equal to $\pi_{i}(\mu, \ldots, \mu)$. Therefore, assume w.l.o.g. that $\lim _{t \rightarrow \infty} \pi_{i}\left(\mu^{t}, \ldots, \mu^{t}\right)=y$ and let $x=\pi_{i}(\mu, \ldots, \mu)$. Since $\sum_{i \in N} \pi_{i}$ is continuous and all firms play the same strategy in a symmetric game, it holds that $n y=\lim _{t \rightarrow \infty} \sum_{i \in N} \pi_{i}\left(\mu^{t}, \ldots, \mu^{t}\right)=$ $\sum_{i \in N} \pi_{i}(\mu, \ldots, \mu)=n x$. Therefore, $x=y$ and $\lim _{t \rightarrow \infty} \pi_{i}\left(\mu^{t}, \ldots, \mu^{t}\right)=\pi_{i}(\mu, \ldots, \mu)$. This implies that each $\pi_{i}(\mu, \ldots, \mu)$ is not only upper semicontinuous as a function of $\mu$ on $P(A)$, but continuous as well.

- Diagonally payoff secure: To proof that our setting is diagonally payoff secure, we have to show that for every $\mu \in P(A)$ and every $\varepsilon>0$, each firm $i$ can secure a payoff $\pi_{i}(\mu, \ldots, \mu)-\varepsilon$ along the diagonal at $(\mu, \ldots, \mu)$. Firm $i$ can secure a payoff of $\pi_{i}(\mu, \ldots, \mu)-\varepsilon$ along the diagonal at $(\mu, \ldots, \mu)$ if there exists a $\bar{\mu} \in P(A)$ such that $\pi_{i}\left(\mu^{\prime}, \ldots, \bar{\mu}, \ldots, \mu^{\prime}\right) \geq \pi_{i}(\mu, \ldots, \mu)-\varepsilon$ for all $\mu^{\prime}$ in some open neighborhood of $\mu \in P(A)$. 
Now, for every $\delta>0$ and every Borel subset $B$ of $A$ define

$$
B^{\delta}:=\left\{\left(p^{\prime}, q\right) \in A \mid \text { there is }(p, q) \in B \text { such that } p^{\prime}=p+\delta\right\}
$$

For a mixed strategy $\mu$ on $A$ define the mixed strategy $\mu^{\delta}$ by

$$
\mu^{\delta}(B):=\mu\left(B^{\delta}\right)+\mu(\{(p, q) \in B \mid p<\delta\})
$$

for every Borel set $B$. Finally, let $\varepsilon>0$ and let $\mu$ be a mixed strategy on $A$. Then there is a $\delta>0$ such that $u_{i}\left(\mu^{\prime}, \ldots, \mu^{\prime}, \mu^{\delta}, \mu^{\prime}, \ldots, \mu^{\prime}\right) \geq u_{i}(\mu, \ldots, \mu)-\varepsilon$ for all $\mu^{\prime}$ close enough to $\mu$. This last line follows because, given that the other firms do not change their mixed strategies too much, if firm $i$ slightly lowers its price, this at most slightly reduces its profit.

Proof of Lemma 3. We prove that $s(\check{p})=\{D(\check{p})\}$ by deriving a contradiction. In our game, the support is compact and therefore $s(\check{p}) \neq \emptyset$.

First, we will show that for all $p \in\left[\check{p}, p^{m}\right]$, it holds that $q \leq D(p)$ for all $q \in s(p)$. Define $B_{\varepsilon}(p, q)$ as the open $\varepsilon$-ball centered at $(p, q)$. Assume $q>D(p)$ and let $\varepsilon>0$ be small enough, such that for all $\left(p_{i}, q_{i}\right) \in B_{\varepsilon}(p, q)$ it holds that $q_{i}>D\left(p_{i}\right)$. Let $(\tilde{p}, \tilde{q})$ be an arbitrary element in $B_{\varepsilon}(p, q)$. Then, given any $\left(\boldsymbol{p}_{-\boldsymbol{i}}, \boldsymbol{q}_{-\boldsymbol{i}}\right)$, the actions chosen by the other $n-1$ firms, firm $i$ 's profit is

$$
\pi_{i}\left(\tilde{p}, \tilde{q}, \boldsymbol{p}_{-\boldsymbol{i}}, \boldsymbol{q}_{-\boldsymbol{i}}\right)=\tilde{p} \frac{\tilde{q}}{\sum_{j \in \Omega(\tilde{p})} q_{j}}\left(D(\tilde{p})-\sum_{k \in \Delta(\tilde{p})} q_{k}\right)^{+}-c \tilde{q}
$$

Instead, if firm $i$ would choose the action $(\tilde{p}-\delta, D(\tilde{p}-\delta))$, where $\delta>0$ is chosen such that $D(\tilde{p}-\delta)<\tilde{q}$ and $\delta D(\tilde{p})<c(\tilde{q}-D(\tilde{p}-\delta))$, its profit is

$$
\pi_{i}\left(\tilde{p}-\delta, D(\tilde{p}-\delta), \boldsymbol{p}_{-\boldsymbol{i}}, \boldsymbol{q}_{-\boldsymbol{i}}\right)=(\tilde{p}-\delta) \frac{\tilde{q}}{\sum_{j \in \Omega(\tilde{p}-\delta)} q_{j}}\left(D(\tilde{p}-\delta)-\sum_{k \in \Delta(\tilde{p}-\delta)} q_{k}\right)^{+}-c D(\tilde{p}-\delta) .
$$

Note that since $D(\tilde{p}-\delta)<\tilde{q}$, it holds that if $\left(D(\tilde{p})-\sum_{k \in \Delta(\tilde{p})} q_{k}\right)^{+}=0$, then $(\tilde{p}-\delta, D(\tilde{p}-\delta))$ 
is a strict improvement over $(\tilde{p}, \tilde{q})$. Now, if $\left(D(\tilde{p})-\sum_{k \in \Delta(\tilde{p})} q_{k}\right)^{+}>0$, then

$$
\begin{aligned}
\pi_{i}\left(\tilde{p}-\delta, D(\tilde{p}-\delta), \boldsymbol{p}_{-\boldsymbol{i}}, \boldsymbol{q}_{-\boldsymbol{i}}\right) & >(\tilde{p}-\delta)\left(D(\tilde{p})-\sum_{k \in \Delta(\tilde{p})} q_{k}\right)-c D(\tilde{p}-\delta) \\
& >(\tilde{p}-\delta)\left(D(\tilde{p})-\sum_{k \in \Delta(\tilde{p})} q_{k}\right)+\delta D(\tilde{p})-c \tilde{q} \\
& =\tilde{p}\left(D(\tilde{p})-\sum_{k \in \Delta(\tilde{p})} q_{k}\right)-c \tilde{q}+\delta \sum_{k \in \Delta(\tilde{p})} q_{k} \\
& \geq \tilde{p}\left(D(\tilde{p})-\sum_{k \in \Delta(\tilde{p})} q_{k}\right)-c \tilde{q} \\
& \geq \tilde{p} \frac{\tilde{q}}{\sum_{j \in \Omega(\tilde{p})} q_{j}}\left(D(\tilde{p})-\sum_{k \in \Delta(\tilde{p})} q_{k}\right)-c \tilde{q} \\
& =\pi_{i}\left(\tilde{p}, \tilde{q}, \boldsymbol{p}_{-\boldsymbol{i}}, \boldsymbol{q}_{-\boldsymbol{i}}\right) .
\end{aligned}
$$

Here, the first inequality holds because of the following. First, note that $\Omega(\tilde{p}-\delta) \backslash\{i\} \cup$ $\Delta(\tilde{p}-\delta) \subseteq \Delta(\tilde{p}), \Omega(\tilde{p}-\delta) \backslash\{i\} \cap \Delta(\tilde{p}-\delta)=\emptyset$ and $D(\tilde{p}-\delta)>D(\tilde{p})$. This gives

$$
\begin{aligned}
D(\tilde{p})-\sum_{k \in \Delta(\tilde{p})} q_{k} & <D(\tilde{p}-\delta)-\sum_{k \in \Delta(\tilde{p}-\delta)} q_{k}-\sum_{j \in \Omega(\tilde{p}-\delta) \backslash\{i\}} q_{j} \\
& \leq \frac{\tilde{q}}{\sum_{j \in \Omega(\tilde{p}-\delta)} q_{j}}\left(D(\tilde{p}-\delta)-\sum_{k \in \Delta(\tilde{p}-\delta)} q_{k}\right) .
\end{aligned}
$$

The second inequality follows from $\delta D(\tilde{p})<c(\tilde{q}-D(\tilde{p}-\delta))$. So, also when the residual demand is strictly positive, the action $(\tilde{p}-\delta, D(\tilde{p}-\delta))$ gives a strictly higher profit then $(\tilde{p}, \tilde{q})$. This implies that, for any $(\tilde{p}, \tilde{q}) \in B_{\varepsilon}(p, q)$, there exists a $\delta$ such that it holds that $(\tilde{p}-\delta, D(\tilde{p}-\delta))$ gives a strictly higher payoff and therefore $q \notin s(p)$.

Next, assume that $q \in s(\check{p})$ and $q<D(\check{p})$. The maximum profit that a firm can make in any point in an open $\varepsilon$-ball centered at $(\check{p}, q)$ is strictly smaller than $(\check{p}+\varepsilon-c)(q+\varepsilon)$. Since $(\check{p}-c) D(\check{p})>(\check{p}-c) q$, as $\varepsilon \rightarrow 0$, there always exists a $\eta>0$ such that

$$
(\check{p}-\eta-c) D(\check{p}-\eta)>(\check{p}+\varepsilon-c)(q+\varepsilon) .
$$

That is, there always exists a price-quantity combination $(\check{p}-\eta, D(\check{p}-\eta))$ that gives a strictly higher profit than any point in $B_{\varepsilon}(\check{p}, q)$. This contradicts $q \in s(\check{p})$. Thus, we conclude $s(\check{p})=\{D(\check{p})\}$.

Suppose there is an atom at price $\check{p}$. In that case, $\pi_{i}\left((\check{p}, D(\check{p})), \boldsymbol{\mu}_{-\boldsymbol{i}}\right)<(\check{p}-c) D(\check{p})$. This implies that there exists a small enough $\delta>0$ such that

$$
\begin{aligned}
\pi_{i}\left((\check{p}-\delta, D(\check{p}-\delta)), \boldsymbol{\mu}_{-i}\right) & =(\check{p}-\delta-c) D(\check{p}-\delta) \\
& >\pi_{i}\left((\check{p}, D(\check{p})), \boldsymbol{\mu}_{-\boldsymbol{i}}\right) .
\end{aligned}
$$


This implies that $\mu_{p}$ does not have an atom at $\check{p}$.

Proof of Lemma 4. First observe that Lemma 3 implies $\check{p}<p^{m}$, because otherwise $\check{p}=p^{m}=\hat{p}$ and $\mu(\{\check{p}\})>0$. Next, we will show that there exists a price $p^{\prime} \in\left(\check{p}, p^{m}\right]$ for which $s\left(p^{\prime}\right)=\left\{D\left(p^{\prime}\right)\right\}$. In the proof of Lemma 3, it is shown that for any $p \in\left[\check{p}, p^{m}\right]$, it holds for all $q>D(p)$ that $q \notin s(p)$. Therefore, given that all $n-1$ rivals stick to their equilibrium strategy, firm $i$ 's profit of choosing $(p, q) \in \operatorname{supp}(\mu)$, is as follows. The expected residual demand of firm $i$, when $m \geq 1$ firms price below, $l$ firms price at the same price and $n-m-l-1$ price above the price of firm $i$, is given by

$$
\begin{aligned}
A\left((p, q), \boldsymbol{\mu}_{-i}\right)= & \left(\sum_{m=1}^{n-1} \sum_{l=0}^{n-1-m} \int_{([\check{p}, p) \times[0, D(c)])^{m} \times(\{p\} \times[0, D(c)])^{l}}\right. \\
& \min \left\{q, \frac{q}{\sum_{j \in \Omega(p)} q_{j}}\left(D(p)-\sum_{k \in \Delta(p)} q_{k}\right)^{+}\right\} d\left(\prod_{j=1}^{m+l} \mu\left(p_{j}, q_{j}\right)\right) \\
& \left.\times \frac{(n-1) !}{(n-1-m) ! m !} \times \frac{(n-1-m) !}{(n-1-m-l) ! l !}\right) \times\left(\mu_{p}((p, \hat{p}])\right)^{n-m-l-1} .
\end{aligned}
$$

The expected residual demand of firm $i$, when $l \geq 1$ firms price at the same price and $n-l-1$ firms price above the price of firm $i$, is given by

$$
\begin{aligned}
B\left((p, q), \boldsymbol{\mu}_{-\boldsymbol{i}}\right)= & \left(\sum_{l=1}^{n-1} \int_{\left(\{p\} \times[0, D(c)]^{l}\right.} \min \left\{q, \frac{q}{\sum_{j \in \Omega(p)} q_{j}} D(p)\right\} d\left(\prod_{j=1}^{l} \mu\left(p_{j}, q_{j}\right)\right)\right. \\
& \left.\times \frac{(n-1) !}{(n-1-l) ! l !}\right) \times\left(\mu_{p}((p, \hat{p}])\right)^{n-l-1} .
\end{aligned}
$$

Therefore, firm $i$ 's expected profit of choosing $(p, q) \in \operatorname{supp}(\mu)$ is

$$
\begin{aligned}
\pi_{i}\left((p, q), \boldsymbol{\mu}_{-i}\right)= & p \times A\left((p, q), \boldsymbol{\mu}_{-i}\right)+p \times B\left((p, q), \boldsymbol{\mu}_{-i}\right) \\
& +p q\left(\mu_{p}((p, \hat{p}])\right)^{n-1}-c q
\end{aligned}
$$

Both $A\left((p, q), \boldsymbol{\mu}_{-\boldsymbol{i}}\right)$ and $B\left((p, q), \boldsymbol{\mu}_{-\boldsymbol{i}}\right)$ are increasing in $q$ for $q \leq D(p)$. Hence, $\pi_{i}\left((p, q), \boldsymbol{\mu}_{-\boldsymbol{i}}\right)$ is strictly increasing in $q$ when $p\left(\mu_{p}((p, \hat{p}])\right)^{n-1}-c>0$.

Since there are at most countably many atoms in $\mu_{p}, \check{p}>c$ and $\mu_{p}(\{\check{p}\})=0$ (Lemma 3), there exists a $p^{\prime} \in\left(\check{p}, p^{m}\right]$ such that $p\left(\mu_{p}((p, \hat{p}])\right)^{n-1}-c>0$ for all $p \in\left(\check{p}, p^{\prime}\right]$ and $s\left(p^{\prime}\right) \neq \emptyset$. We now show that $s(p)=\{D(p)\}$ or $s(p)=\emptyset$ for all $p \in\left(\check{p}, p^{\prime}\right]$. Assume $p \in\left(\check{p}, p^{\prime}\right], q \in s(p)$ and $q<D(p)$. Define $B_{\varepsilon}(p, q)$ as the open $\varepsilon$-ball centered at $(p, q)$ and let $\varepsilon>0$ be small enough, such that for all $\left(p_{i}, q_{i}\right) \in B_{\varepsilon}(p, q)$ it holds that $q_{i}<D\left(p_{i}\right), p_{i}\left(\mu_{p}\left(\left(p_{i}, \hat{p}\right]\right)\right)^{n-1}-c>0$ 
and $p_{i}>\check{p}$. Let $(\tilde{p}, \tilde{q})$ be an arbitrary element in $B_{\varepsilon}(p, q)$. Then, since the profit of firm $i$ is increasing in $q$ for $q \leq D(p)$, firm $i$ strictly improves its profits by choosing $(\tilde{p}, D(\tilde{p}))$. Therefore, for any $(\tilde{p}, \tilde{q}) \in B_{\varepsilon}(p, q)$ there is another combination of price and quantity that will give a strictly higher payoff and therefore $q \notin s(p)$. In the proof of Lemma 3 , it is shown that for all $q \in s(p)$ it holds that $q \leq D(p)$. This gives $s(p)=\{D(p)\}$ or $s(p)=\emptyset$ for all $p \in\left(\check{p}, p^{\prime}\right]$. Since $s\left(p^{\prime}\right) \neq \emptyset$, it holds that $s\left(p^{\prime}\right)=\left\{D\left(p^{\prime}\right)\right\}$.

Now suppose that $\mu_{p}$ has an atom at some price $p \in\left(\check{p}, p^{\prime}\right]$. The measure $\mu_{p}$ has at most countably many atoms, which implies that there exists a small enough $\delta>0$ such that $p-\delta>\check{p}, \mu_{p}(\{p-\delta\})=0$ and

$$
\begin{aligned}
\pi_{i}\left((p-\delta, D(p-\delta)), \boldsymbol{\mu}_{-i}\right) & \left.=(p-\delta) D(p-\delta) \mu_{p}((p-\delta, \hat{p}])\right)^{n-1}-c D(p-\delta) \\
& \left.\geq(p-\delta) D(p-\delta) \mu_{p}([p, \hat{p}])\right)^{n-1}-c D(p-\delta) \\
& >p D(p)\left(\sum_{l=0}^{n-1} \frac{1}{n-l} \mu_{p}(\{p\})^{n-1-l} \mu((p, \hat{p}])^{l} \times \frac{(n-1) !}{(n-1-l) ! l !}\right)-c D(p) \\
& =\pi_{i}\left((p, D(p)), \boldsymbol{\mu}_{-i}\right) .
\end{aligned}
$$

In the third line, $l$ represents the number of firms that price at the same level as firm $i$. Since there is an atom at $p$, the probability of $l$ being strictly positive is strictly bigger than 0 , hence the inequality before the third line. Consequently, $\mu_{p}$ cannot have an atom at any price $p \in\left(\check{p}, p^{\prime}\right]$.

Finally, we show that $s(p)=\{D(p)\}$ for all $p \in\left(\check{p}, p^{\prime}\right]$. Assume that $s(p)=\emptyset$ for all $p$ in some interval $(\alpha, \beta) \subseteq\left(\check{p}, p^{\prime}\right)$. This implies that, for $p \in(\alpha, \beta)$,

$$
\pi_{i}\left((p, D(p)), \boldsymbol{\mu}_{-i}\right)=p D(p)\left(\mu_{p}([\beta, \hat{p}])\right)^{n-1}-c D(p) .
$$

It follows from $\beta \leq p^{m}$ and $D^{\prime}(p)(p-c)+D(p)>0$ for all $p \in(\alpha, \beta)$, that $\pi_{i}\left((p, D(p)), \boldsymbol{\mu}_{-i}\right)$ is strictly increasing for all $p \in(\alpha, \beta)$.

Now, the maximum profit that a firm can make in any point in an open $\varepsilon$-ball centered at $(\alpha, D(\alpha))$ is strictly smaller than $(\alpha+\varepsilon) D(\alpha+\varepsilon) \mu_{p}((\alpha-\varepsilon, \check{p}])-c D(\alpha+\varepsilon)$. Since $\pi_{i}\left((p, D(p)), \boldsymbol{\mu}_{-i}\right)$ is strictly increasing for all $p \in(\alpha, \beta)$ and $\mu_{p}$ does not have an atom at any price $p \in\left(\check{p}, p^{\prime}\right]$, as $\varepsilon \rightarrow 0$, there always exists $\gamma \in(\alpha, \beta)$ such that

$$
\pi_{i}\left((\gamma, D(\gamma)), \boldsymbol{\mu}_{-i}\right)>(\alpha+\varepsilon) D(\alpha+\varepsilon) \mu_{p}((\alpha-\varepsilon, \check{p}])-c D(\alpha+\varepsilon)
$$

That is, there always exists a price-quantity combination $(\gamma, D(\gamma))$ that gives a strictly higher 
profit than any point in $B_{\varepsilon}(\alpha, D(\alpha))$. This contradicts $(\alpha, D(\alpha)) \in \operatorname{supp}(\mu)$. Thus, we conclude that $s(p)=\{D(p)\}$ for all $p \in\left(\check{p}, p^{\prime}\right]$.

Proof of Theorem 5. Suppose $\check{p}>c$ and let $p^{u}=\sup \left\{p^{\prime} \in\left[\check{p}, p^{m}\right] \mid \forall p \in\left[\check{p}, p^{\prime}\right): s(p)=\right.$ $\{D(p)\}$ and $\left.\mu_{p}(\{p\})=0\right\}$. From Lemma 4 it follows that $p^{u}>\check{p}$. Moreover, since the support of a measure is closed, $D\left(p^{u}\right) \in s\left(p^{u}\right)$.

Since $\mu_{p}(\{p\})=0$ for all $p \in\left[\check{p}, p^{u}\right)$, it follows directly from the proof of Lemma 4 that $\pi^{*}=D(p)\left[p\left(\mu_{p}((p, \hat{p}])\right)^{n-1}-c\right]$ for all $p \in\left[\check{p}, p^{u}\right)$. As $\pi^{*} \geq 0$, it follows that

$$
\begin{aligned}
p^{u}\left(\mu_{p}\left(\left[p^{u}, \hat{p}\right]\right)\right)^{n-1}-c & =\lim _{p \uparrow p^{u}} p\left(\mu_{p}((p, \hat{p}])\right)^{n-1}-c \\
& \geq 0 .
\end{aligned}
$$

Hence, there are two possibilities. Either $p^{u}\left(\mu_{p}\left(\left[p^{u}, \hat{p}\right]\right)\right)^{n-1}-c=0$ or $p^{u}\left(\mu_{p}\left(\left[p^{u}, \hat{p}\right]\right)\right)^{n-1}-c>$ 0 .

Suppose that $p^{u}\left(\mu_{p}\left(\left[p^{u}, \hat{p}\right]\right)\right)^{n-1}-c=0$. Then it follows from $\mu(\{p\})=0$ for all $p \in\left[\check{p}, p^{u}\right)$ that

$$
\begin{aligned}
\pi^{*} & =\lim _{p \uparrow p^{u}} D(p)\left[p\left(\mu_{p}((p, \hat{p}])\right)^{n-1}-c\right] \\
& =D\left(p^{u}\right)\left[p^{u}\left(\mu_{p}\left(\left[p^{u}, \hat{p}\right]\right)\right)^{n-1}-c\right] \\
& =0 .
\end{aligned}
$$

This implies that $p\left(\mu_{p}((p, \hat{p}])\right)^{n-1}-c=0$ for all $p \in\left[\check{p}, p^{u}\right)$. Since $\mu(\{\check{p}\})=0$, it follows that $\left(\mu_{p}((\check{p}, \hat{p}])\right)^{n-1}=1$ and therefore $\check{p}=c$.

Now suppose that $p^{u}\left(\mu_{p}\left(\left[p^{u}, \hat{p}\right]\right)\right)^{n-1}-c>0$. If this is the case, it must hold that $\mu_{p}\left(\left\{p^{u}\right\}\right)>0$. Suppose the contrary, i.e. $\mu_{p}\left(\left\{p^{u}\right\}\right)=0$. Then there exists a $\tilde{p}>p^{u}$ for which it holds that $\tilde{p}\left(\mu_{p}((\tilde{p}, \hat{p}])\right)^{n-1}-c>0$. From the proof of Lemma 4 it follows that $s(p)=\{D(p)\}$ and $\mu_{p}(\{p\})=0$ for all $p \in[\check{p}, \tilde{p})$. This contradicts the definition of $p^{u}$. Hence, $\mu_{p}\left(\left\{p^{u}\right\}\right)>0$. Given that $\mu_{p}\left(\left\{p^{u}\right\}\right)>0$, for every $q<D\left(p^{u}\right)$, there exists a $\delta>0$ such that

$$
\begin{aligned}
\pi_{i}\left(\left(p^{u}, q\right), \boldsymbol{\mu}_{-i}\right) & \leq q\left[p^{u}\left(\mu_{p}\left(\left[p^{u}, \hat{p}\right]\right)\right)^{n-1}-c\right] \\
& <D\left(p^{u}-\delta\right)\left[\left(p^{u}-\delta\right)\left(\mu_{p}\left(\left(p^{u}-\delta, \hat{p}\right]\right)\right)^{n-1}-c\right] \\
& =\pi_{i}\left(\left(p^{u}-\delta, D\left(p^{u}-\delta\right)\right), \boldsymbol{\mu}_{-\boldsymbol{i}}\right) \\
& =\pi^{*} .
\end{aligned}
$$


The first inequality follows since firm $i$ sells at most $q$. Since $q<D\left(p^{u}\right)$ and $\lim _{p \uparrow p^{u}} D(p)\left[p\left(\mu_{p}((p, \hat{p}])\right)^{n-1}-\right.$ $c]=D\left(p^{u}\right)\left[p^{u}\left(\mu_{p}\left(\left[p^{u}, \hat{p}\right]\right)\right)^{n-1}-c\right]$, the second inequality is strict for a small enough $\delta$.

Now, for $q=D\left(p^{u}\right)$ it holds for all $0<\delta \leq p^{u}-\check{p}$ that

$$
\begin{aligned}
\pi_{i}\left(\left(p^{u}, D\left(p^{u}\right)\right), \boldsymbol{\mu}_{-i}\right) & <D\left(p^{u}\right)\left[p^{u}\left(\mu_{p}\left(\left[p^{u}, \hat{p}\right]\right)\right)^{n-1}-c\right] \\
& =\lim _{p \uparrow p^{u}} D(p)\left[p\left(\mu_{p}((p, \hat{p}])\right)^{n-1}-c\right] \\
& =D\left(p^{u}-\delta\right)\left[\left(p^{u}-\delta\right)\left(\mu_{p}\left(\left(p^{u}-\delta, \hat{p}\right]\right)\right)^{n-1}-c\right] \\
& =\pi^{*} .
\end{aligned}
$$

Since there is an atom at $p^{u}$, firm $i$ expects to sell strictly less than $D\left(p^{u}\right)$ when it sets a price of $p^{u}$. Hence, the first inequality is strict and the equalities follow immediately.

So, given that $\mu_{p}\left(\left\{p^{u}\right\}\right)>0$, for any combination $\left(p^{u}, q\right)$ there exists a $\delta>0$ such that it holds that $\left(p^{u}-\delta, D\left(p^{u}-\delta\right)\right)$ gives a strictly higher payoff. Therefore, this second situation cannot occur. Thus, we conclude that $\check{p}=c$ and $\pi^{*}=0$.

Proof of Lemma 7. As we consider a price cartel, firms are free in choosing their production levels. Therefore, it is sufficient to analyze the impact of output decisions on per-period profits. Given a fixed cartel price $p^{c} \in\left(c, p^{m}\right]$, per-period profit for every firm $i \in N$ is

$$
\pi_{i}^{c}\left(p^{c}, \mathbf{q}\right)=p^{c} D_{i}\left(p^{c}, \mathbf{q}\right)-c q_{i}
$$

where firm demand is given by

$$
D_{i}\left(p^{c}, \mathbf{q}\right)= \begin{cases}q_{i} & \text { if } \sum_{j \in N} q_{j} \leq D\left(p^{c}\right) \\ \frac{q_{i}}{\sum_{j \in N} q_{j}} D\left(p^{c}\right) & \text { if } \sum_{j \in N} q_{j}>D\left(p^{c}\right) .\end{cases}
$$

The following first-order condition specifies the impact of a change in the level of individual production on per-period profit.

$$
\frac{d \pi_{i}^{c}\left(p^{c}, \mathbf{q}\right)}{d q_{i}}= \begin{cases}p^{c}-c & \text { if } q_{i} \leq D\left(p^{c}\right)-\sum_{j \in N \backslash\{i\}} q_{j} \\ p^{c} \frac{\sum_{j \in N \backslash\{i\}} q_{j}}{\left(\sum_{j \in N} q_{j}\right)^{2}} D\left(p^{c}\right)-c & \text { if } q_{i}>D\left(p^{c}\right)-\sum_{j \in N \backslash\{i\}} q_{j} .\end{cases}
$$

Hence, as $p^{c}>c$, the profit of firm $i$ is increasing in its production level as long as $q_{i} \leq$ $D\left(p^{c}\right)-\sum_{j \in N \backslash\{i\}} q_{j}$. Yet, profits may increase even more for output levels that make aggregate supply exceed market demand. This requires

$$
p^{c} \frac{\sum_{j \in N \backslash\{i\}} q_{j}}{\left(\sum_{j \in N} q_{j}\right)^{2}} D\left(p^{c}\right)-c \geq 0,
$$


or

$$
q_{i} \leq \sqrt{\frac{p^{c} D\left(p^{c}\right)\left(\sum_{j \in N \backslash\{i\}} q_{j}\right)}{c}}-\sum_{j \in N \backslash\{i\}} q_{j} .
$$

Therefore, this case applies when there exists a production level $q_{i}$ for which the following condition is satisfied

$$
D\left(p^{c}\right)-\sum_{j \in N \backslash\{i\}} q_{j}<q_{i} \leq \sqrt{\frac{p^{c} D\left(p^{c}\right)\left(\sum_{j \in N \backslash\{i\}} q_{j}\right)}{c}}-\sum_{j \in N \backslash\{i\}} q_{j} .
$$

This is possible if and only if

$$
\sum_{j \in N \backslash\{i\}} q_{j}>\frac{D\left(p^{c}\right) c}{p^{c}} .
$$

Thus, we can conclude that $q_{i}^{*}\left(p^{c}, \mathbf{q}_{-\mathbf{i}}\right)=D\left(p^{c}\right)-\sum_{j \in N \backslash\{i\}} q_{j}$ if $\sum_{j \in N \backslash\{i\}} q_{j} \leq \frac{D\left(p^{c}\right) c}{p^{c}}$. Moreover, if $\sum_{j \in N \backslash\{i\}} q_{j}>\frac{D\left(p^{c}\right) c}{p^{c}}$, then $q_{i}^{*}\left(p^{c}, \mathbf{q}_{-\mathbf{i}}\right)=\sqrt{\frac{p^{c} D\left(p^{c}\right)\left(\sum_{j \in N \backslash\{i\}} q_{j}\right)}{c}}-\sum_{j \in N \backslash\{i\}} q_{j}$ provided that this yields more profit than with zero production. Producing nothing is strictly preferred when the following two equations hold simultaneously:

$$
D\left(p^{c}\right)-\sum_{j \in N \backslash\{i\}} q_{j}<0
$$

and

$$
p^{c} \frac{\sum_{j \in N \backslash\{i\}} q_{j}}{\left(\sum_{j \in N} q_{j}\right)^{2}} D\left(p^{c}\right)-c<0 .
$$

If $q_{i}=0$, then $\sum_{j \in N} q_{j}=\sum_{j \in N \backslash\{i\}} q_{j}$. Substituting in (13) and rearranging gives

$$
\sum_{j \in N \backslash\{i\}} q_{j}>\frac{D\left(p^{c}\right) p^{c}}{c} .
$$

Notice that (14) implies (12). Hence, (14) is a sufficient condition under which firm $i$ finds it optimal to produce nothing. We therefore conclude that $q_{i}^{*}\left(p^{c}, \mathbf{q}_{-\mathbf{i}}\right)=\sqrt{\frac{p^{c} D\left(p^{c}\right)\left(\sum_{j \in N \backslash\{i\}} q_{j}\right)}{c}}-$ $\sum_{j \in N \backslash\{i\}} q_{j}$ if $\frac{D\left(p^{c}\right) c}{p^{c}}<\sum_{j \in N \backslash\{i\}} q_{j} \leq \frac{D\left(p^{c}\right) p^{c}}{c}$ and $q_{i}^{*}\left(p^{c}, \mathbf{q}_{-\mathbf{i}}\right)=0$ if $\sum_{j \in N \backslash\{i\}} q_{j}>\frac{D\left(p^{c}\right) p^{c}}{c}$.

Proof of Lemma 8. Let $m=\sum_{k \in N \backslash\{v, w\}} q_{k}$. Hence,

$$
q_{v}^{*}=\sqrt{\frac{p^{c} D\left(p^{c}\right)\left(m+q_{w}^{*}\right)}{c}}-\left(m+q_{w}^{*}\right),
$$


and

$$
q_{w}^{*}=\sqrt{\frac{p^{c} D\left(p^{c}\right)\left(m+q_{v}^{*}\right)}{c}}-\left(m+q_{v}^{*}\right)
$$

Substituting $q_{w}^{*}$ in $q_{v}^{*}$ yields

$$
4 q_{v}^{* 2}+\left(4 m-\frac{p^{c} D\left(p^{c}\right)}{c}\right) q_{v}^{*}-m\left(\frac{p^{c} D\left(p^{c}\right)}{c}-m\right)=0 .
$$

Solving for $q_{v}^{*}$ gives

$$
q_{v}^{*}=\frac{-\left(4 m-\frac{p^{c} D\left(p^{c}\right)}{c}\right) \pm \sqrt{\frac{p^{c} D\left(p^{c}\right)}{c}\left(8 m+\frac{p^{c} D\left(p^{c}\right)}{c}\right)}}{8} .
$$

There is a unique solution for which $q_{v}^{*}>0$. As we have a similar expression for $q_{w}^{*}$, we conclude $q_{v}^{*}=q_{w}^{*}$.

Proof of Theorem 9. For a given cartel price $p^{c}$, a cartel contract $\left(p^{c}, \mathbf{q}\right)$ is a subgame perfect Nash equilibrium when none of the firms has an incentive to change its production level given the output of rivals. There are two possibilities. For all $i \in N$, either $(i) \sum_{j \in N \backslash\{i\}} q_{j} \leq$ $D\left(p^{c}\right) c / p^{c}$, or $(i i) D\left(p^{c}\right) c / p^{c}<\sum_{j \in N \backslash\{i\}} q_{j} \leq D\left(p^{c}\right) p^{c} / c$.

(i) By Lemma 7, it holds that $q_{i}^{*}\left(p^{c}, \mathbf{q}_{-\mathbf{i}}\right)=D\left(p^{c}\right)-\sum_{j \in N \backslash\{i\}} q_{j}$ for all $i \in N$. As $D\left(p^{c}\right)-\sum_{j \in N \backslash\{i\}} q_{j} \geq D\left(p^{c}\right)-\frac{D\left(p^{c}\right) c}{p^{c}}$, it follows that $q_{i}^{*}\left(p^{c}, \mathbf{q}_{-\mathbf{i}}\right) \geq \frac{p^{c}-c}{p^{c}} D\left(p^{c}\right)$.

In turn, this implies

$$
n \frac{p^{c}-c}{p^{c}} D\left(p^{c}\right) \leq D\left(p^{c}\right)
$$

Rearranging gives

$$
p^{c} \leq \frac{c n}{n-1}
$$

(ii) By Lemma 7, it holds that $q_{i}^{*}\left(p^{c}, \mathbf{q}_{-\mathbf{i}}\right)=\sqrt{\frac{p^{c} D\left(p^{c}\right)\left(\sum_{j \in N \backslash\{i\}} q_{j}\right)}{c}}-\sum_{j \in N \backslash\{i\}} q_{j}$ for all $i \in N$. In this case, we know by Lemma 8 that all firms produce the same quantity. Therefore, $q_{i}^{*}\left(p^{c}, \mathbf{q}_{-\mathbf{i}}\right)=\sqrt{\frac{p^{c} D\left(p^{c}\right)\left(\sum_{j \in N \backslash\{i\}} q_{j}\right)}{c}}-\sum_{j \in N \backslash\{i\}} q_{j}=\sqrt{\frac{p^{c} D\left(p^{c}\right)(n-1) q_{i}^{*}\left(p^{c}, \mathbf{q}_{-\mathbf{i}}\right)}{c}}-(n-1) q_{i}^{*}\left(p^{c}, \mathbf{q}_{-\mathbf{i}}\right)$.

Rearranging gives

$$
q_{i}^{*}\left(p^{c}, \mathbf{q}_{-\mathbf{i}}\right)=\frac{p^{c} D\left(p^{c}\right)(n-1)}{c n^{2}} .
$$


As $D\left(p^{c}\right) c / p^{c}<\sum_{j \in N \backslash\{i\}} q_{j}$, it follows that $(n-1) q_{i}^{*}=\frac{p^{c}(n-1)^{2} D\left(p^{c}\right)}{c n^{2}}>D\left(p^{c}\right) c / p^{c}$.

Rearranging gives

$$
p^{c}>\frac{c n}{n-1} .
$$

Finally, it should also hold that $(n-1) q_{i}^{*} \leq D\left(p^{c}\right) p^{c} / c$, which is true as $\frac{(n-1)^{2}}{n^{2}}<1$.

Proof of Theorem 12. If $p^{m} \leq \frac{c n}{n-1}$, then $p^{c} \leq \frac{c n}{n-1}$. By Theorem $9, q_{i}^{*}=D\left(p^{c}\right)-$ $\sum_{j \in N / i} q_{j}^{*}$. In this case, the incentive compatibility constraint is given by

$$
\delta \geq \delta_{i}^{*}=1-\frac{q_{i}^{*}}{\sum_{j \in N} q_{j}^{*}}, \text { for all } i \in N .
$$

Hence, the critical discount factor is highest for the firm(s) with the lowest level of sales. Clearly, if $\delta \geq \delta_{i}^{*}$ for all $i \in N$, then there exists both a viable price cartel and a price-quota cartel. If $1-\frac{1}{n} \leq \delta<1-\frac{q_{i}^{*}}{\sum_{j \in N} q_{j}^{*}}$ for some firm $i \in N$, then a price cartel is not viable. In this case, the cartel is only viable when a sufficiently large share of market demand is allocated to the smallest cartel member(s). There exists an allocation of sales for which the price-quota cartel is viable, because $\delta \geq 1-\frac{1}{n}$.

Proof of Theorem 13. If $p^{m}>\frac{c n}{n-1}$, then $p^{c}<p^{m}$ and $q_{i}^{*}=\frac{(n-1) p^{c} D\left(p^{c}\right)}{c n^{2}}$ for all $i \in N$. Moreover, $\sum_{i \in N} q_{i}^{*} \geq D\left(p^{c}\right)$. The collusive value of every member of a price cartel is then given by $V_{i}\left(p^{c}, \mathbf{q}^{*}\right)=\frac{\frac{q_{i}^{*}}{\sum_{i \in N} q_{i}^{*}}\left(p^{c} D\left(p^{c}\right)-c \sum_{i \in N} q_{i}^{*}\right)}{1-\delta}$. Clearly, keeping the cartel price and market shares fixed, eliminating all excess supply increases the collusive value of every member. This would yield a situation in which all firms produce $\frac{D\left(p^{c}\right)}{n}$ and the market clears. In this case, firms optimally set the monopoly price, which is sustainable as $\delta \geq 1-\frac{1}{n}$ by assumption.

Proof of Theorem 14. See proof of Theorem 12. 


\section{References}

[1] Athey, Susan and Kyle Bagwell (2001), "Optimal Collusion with Private Information," RAND Journal of Economics, 32(3), 428-465;

[2] Athey, Susan, Kyle Bagwell and Chris Sanchirico (2004), "Collusion and Price Rigidity," Review of Economic Studies, 71(2), 317-349;

[3] Benoit, Jean-Pierre and Vijay Krishna (1987), "Dynamic Duopoly: Prices and Quantities," Review of Economic Studies, 54(1), 23-35;

[4] Bos, Iwan and Joseph E. Harrington Jr. (2010), "Endogenous Cartel Formation with Heterogeneous Firms," RAND Journal of Economics, 41(1), 92-117;

[5] Choi, E. Kwan, Carmen F. Menezes and John H. Tressler (1985), "A Theory of PriceFixing Rings," Quarterly Journal of Economics, 100(2), 465-478;

[6] Connor, John (2001), "Our Customers are our Enemies: the Lysine Cartel of 1992-1995," Review of Industrial Organization, 18, 5-21;

[7] Davidson, Carl and Raymond Deneckere (1990), "Excess Capacity and Collusion," International Economic Review, 31(3), 521-541;

[8] De Roos, Nicolas (2006), "Examining Models of Collusion: the Market for Lysine," International Journal of Industrial Organization, 24, 1083-1107;

[9] Dixon, Huw D. (1992), "The Competitive Outcome as the Equilibrium in an Edgeworthian Price-Quantity Model," Economic Journal, 102 (411), 301-309;

[10] Fershtman, Chaim and Eitan Muller (1986), "Capital Investments and Price Agreements in Semicollusive Markets," RAND Journal of Economics, 17(2), 214-226;

[11] Friedman, James W. (1988), "On the Strategic Importance of Prices versus Quantities," RAND Journal of Economics, 19(4), 607-622;

[12] Green, Edward J. and Robert H. Porter (1984), "Noncooperative Collusion under Imperfect Price Information," Econometrica, 52(1), 87-100; 
[13] Harrington, Joseph E. Jr. and Andrzej Skrzypacz (2007), "Collusion under Monitoring of Sales," RAND Journal of Economics, 38(2), 314-331;

[14] Harrington, Joseph E. Jr. and Andrzej Skrzypacz (2010), "Private Monitoring and Communication in Cartels: Explaining Recent Collusive Practices," American Economic Review, forthcoming;

[15] Harrington, Joseph E. Jr. (1991), "The Determination of Price and Output Quotas in a Heterogeneous Cartel," International Economic Review, 32(4), 767-792;

[16] Harrington, Joseph E. Jr. (2006), "How Do Cartels Operate?," Foundations and Trends in Microeconomics, 2(1), 1-105;

[17] Hörner, Johannes and Julian Jamison (2007), "Collusion with (Almost) No Information," RAND Journal of Economics, 38(3), 804-822;

[18] Kreps, David M. and Jose A. Scheinkman (1983), "Quantity Precommitment and Bertrand Competition Yield Cournot Outcomes," Bell Journal of Economics, 14(2), $326-337$;

[19] Osborne, Dale K. (1976), "Cartel Problems," American Economic Review, 66(5), 835844

[20] Reny, Philip J. (1999), "On the Existence of Pure and Mixed Strategy Nash Equilibria in Discontinuous Games," Econometrica, 67(5), 1029-1056;

[21] Rotemberg, Julio J. and Garth Saloner (1989), "The Cyclical Behavior of Strategic Inventories," Quarterly Journal of Economics, 104(1), 73-97;

[22] Russo, Francesco, Maarten Pieter Schinkel, Andrea Günster and Martin Carree (2010), "European Commission Decisions on Competition: Economic Perspectives on Landmark Antitrust and Merger Cases," New York: Cambridge University Press;

[23] Steen, Frode and Lars Sørgard (2009), "Semicollusion," Foundations and Trends in Microeconomics, 5(3), 153-228;

[24] Tasnádi, Attila (2004), "Production in Advance versus Production to Order," Journal of Economic Behavior \& Organization, 54, 191-204; 
[25] Tasnádi, Attila (2006), "Price vs. Quantity in Oligopoly Games," International Journal of Industrial Organization, 24(3), 541-554;

[26] Van den Berg, Anita, Iwan Bos, Jean-Jacques Herings and Hans Peters (2011), "Dynamic Cournot Duopoly with Intertemporal Capacity Constraints," mimeo. 